University of North Florida

UNIVERSITY of

NORTH FLORIDA.

UNF Digital Commons

$6-2006$

\title{
Structure Prediction of Ordered and Disordered Multiple Octahedral Cation Perovskites using SPuDS
}

Michael W. Lufaso

University of North Florida, michael.lufaso@unf.edu

Paris W. Barnes

Patrick M. Woodward

Follow this and additional works at: https://digitalcommons.unf.edu/achm_facpub

Part of the Chemistry Commons

\section{Recommended Citation}

Lufaso, Michael W.; Barnes, Paris W.; and Woodward, Patrick M., "Structure Prediction of Ordered and Disordered Multiple Octahedral Cation Perovskites using SPuDS" (2006). Chemistry Faculty Publications. 1.

https://digitalcommons.unf.edu/achm_facpub/1

This Article is brought to you for free and open access by the Department of Chemistry at UNF Digital Commons. It has been accepted for inclusion in Chemistry Faculty Publications by an authorized administrator of UNF Digital Commons. For more information, please contact Digital Projects.

(c) 6-2006 All Rights Reserved

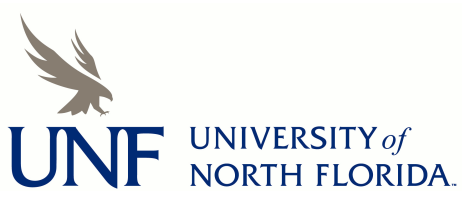


Acta Crystallographica Section B

Structural

Science

ISSN 0108-7681

Michael W. Lufaso,‡ Paris W. Barnes§ and Patrick $M$. Woodward*

Ohio State University, Columbus, $\mathrm{OH} 43210$, USA

₹ Current Address: Department of Chemistry and Biochemistry, University of South Carolina, 631 Sumter Street, Columbia, SC 29208, USA. $\S$ Current Address: Materials Science Division, MSD 223, Argonne National Laboratory, Argonne, IL 60439, USA.

Correspondence e-mail: woodward@chemistry.ohio-state.edu

\section{Structure prediction of ordered and disordered multiple octahedral cation perovskites using SPuDS}

The software package $S P u D S$ has previously been shown to accurately predict crystal structures of $A M X_{3}$ and $A_{1-x} A^{\prime}{ }_{x} M X_{3}$ perovskites that have undergone octahedral tilting distortions. This paper describes the extension of this technique and its accuracy for $A_{2} M M^{\prime} X_{6}$ ordered double perovskites with the aristotype $F m \overline{3} m$ cubic structure, as well as those that have undergone octahedral tilting distortions. A survey of the literature shows that roughly $70 \%$ of all ordered double perovskites undergo octahedral tilting distortions. Of the 11 distinct types of octahedral tilting that can occur in ordered perovskites, five tilt systems account for $\sim 97 \%$ of the reported structures. SPuDS can calculate structures for the five dominant tilt systems, $\operatorname{Fm} \overline{3} m\left(a^{0} a^{0} a^{0}\right), I 4 / m\left(a^{0} a^{0} c^{-}\right), R \overline{3}$ $\left(a^{-} a^{-} a^{-}\right), I 2 / m\left(a^{0} b^{-} b^{-}\right)$and $P 2_{1} / n\left(a^{-} a^{-} b^{+}\right)$, as well as two additional tilt systems, $P n \overline{3}\left(a^{+} a^{+} a^{+}\right)$and $P 4 / m n c\left(a^{0} a^{0} c^{+}\right)$. Comparison with reported crystal structures shows that $S P u D S$ is quite accurate at predicting distortions driven by octahedral tilting. The favored modes of octahedral tilting in ordered double perovskites are compared and contrasted with those in $A M X_{3}$ perovskites. Unit-cell pseudosymmetry in $\mathrm{Sr}-$ and Ca-containing double perovskites is also examined. Experimentally, $\mathrm{Sr}_{2} M M^{\prime} \mathrm{O}_{6}$ compounds show a much stronger tendency toward pseudosymmetry than do $\mathrm{Ca}_{2} M M^{\prime} \mathrm{O}_{6}$ compounds with similar tolerance factors.

\section{Introduction}

Structures in the $A M X_{3}$ family of perovskites have been extensively investigated because of the considerable interest in structural variations and their correlation with physical properties. The perovskite material class exhibits interesting and diverse physical properties including ferroelectricity, piezoelectricity, superconductivity, magnetoresistance and ionic conductivity, among others. All of these physical properties are sensitive to subtle changes in the structure, particularly those that result from tilting of octahedra. Consequently, the crystal structures of many perovskites have been investigated, as have the favored modes of octahedral tilting in ternary $A M X_{3}$ perovskites (Lufaso \& Woodward, 2001). Introducing two or more cations on the octahedral site (i.e. $M$ and $M^{\prime}$ in $A M_{1-x} M_{x}^{\prime} \mathrm{O}_{3}$ ) greatly expands the perovskite family, to the extent that perovskites make up one of the largest families of complex oxides. The scope of the perovskite family is further expanded when non-oxide (halides, sulfides, oxynitrides etc.) compositions are included. If the charge difference between $M$ and $M^{\prime}$ is small and the ionic radii are similar then the two different octahedral cations may form a solid solution with a disordered octahedral cation sublattice. More commonly the octahedral cations adopt an ordered or partially ordered distribution. Ordering of the octahedral
Received 10 June 2005

Accepted 20 January 2006
(C) 2006 International Union of Crystallography Printed in Great Britain - all rights reserved 
Table 1

The 12 tilt systems, space groups, degrees of freedom, number of independent Wyckoff sites and number of observed structures reported for 1:1 rock-salt ordered double perovskites with the restriction that not more than two layers show independent tilting.

\begin{tabular}{|c|c|c|c|c|c|c|c|}
\hline \multirow{2}{*}{$\begin{array}{l}\text { Glazer tilt } \\
\text { system } \dagger\end{array}$} & \multirow[b]{2}{*}{ Space group } & \multirow{2}{*}{$\begin{array}{l}\text { Degrees } \\
\text { of } \\
\text { freedom }\end{array}$} & \multicolumn{3}{|c|}{ Wyckoff sites } & \multicolumn{2}{|c|}{ Frequency } \\
\hline & & & $A$ & $M / M^{\prime}$ & $X$ & Oxides & Halides \\
\hline \multicolumn{8}{|c|}{ Group $A$ - Single $A$ site } \\
\hline$a^{0} a^{0} a^{0}(23)$ & $F m \overline{3} m$ (No. 225$)$ & 2 & 1 & 2 & 1 & 94 & 94 \\
\hline$a^{-} a^{-} a^{-}(14)$ & $R \overline{3}($ No. 148$)$ & 7 & 1 & 2 & 1 & 15 & 0 \\
\hline$a^{0} a^{0} c^{-}$(22) & $I 4 / m$ (No. 87) & 5 & 1 & 2 & 2 & 27 & 2 \\
\hline$a^{0} a^{0} c^{+}(21)$ & P4/mnc (No. 128) & 5 & 1 & 2 & 2 & 1 & 0 \\
\hline$a^{0} b^{-} b^{-}(20)$ & $I 2 / m$ (No. 12) & 11 & 1 & 2 & 2 & 13 & 0 \\
\hline$a^{-} a^{-} b^{+}(10)$ & $P 2_{1} / n($ No. 14$)$ & 16 & 1 & 2 & 3 & 168 & 3 \\
\hline$a^{-} b^{-} c^{-}(12)$ & $I \overline{1}$ (No. 2) & 18 & 1 & 2 & 3 & 7 & 0 \\
\hline \multicolumn{8}{|c|}{ Group $B-$ Multiple $A$ Site } \\
\hline$a^{+} a^{+} a^{+}(3)$ & $\operatorname{Pn} \overline{3}($ No. 201) & 4 & 2 & 2 & 1 & 3 & 0 \\
\hline$a^{0} b^{-} c^{+}(17)$ & $C 2 / c($ No. 15$)$ & 15 & 2 & 2 & 3 & 0 & 0 \\
\hline$a^{0} b^{+} b^{+}(16)$ & $P 4_{2} /$ nnm (No. 134) & 7 & 3 & 2 & 2 & 0 & 0 \\
\hline$a^{+} a^{+} c^{-}(5)$ & $P 4_{2} / n($ No. 86$)$ & 12 & 3 & 2 & 3 & 0 & 0 \\
\hline$a^{+} b^{+} c^{+}(1)$ & Pnnn (No. 48) & 12 & 4 & 2 & 3 & 0 & 0 \\
\hline
\end{tabular}

$\dagger$ The number in parentheses corresponds to the numbering of the tilt systems originally adopted by Glazer (1972).

cations is particularly common when $x=\frac{1}{2}, \frac{1}{3}$ or $\frac{1}{4}$ and there is a large difference in the ionic radii and/or oxidation states of the octahedral cations. The most frequently reported type of $M$-site cation ordering, with $x=\frac{1}{2}$, is described as an ordered double perovskite with the formula written as $A_{2} M M^{\prime} X_{6}$ (Anderson et al., 1993).

Rock-salt-type cation ordering, in which the octahedral cation sublattice adopts a topology analogous to that of $\mathrm{NaCl}$, is the most commonly observed type of $M$-cation ordering in perovskites. Rock-salt (1:1) ordering of the $M$-site cations doubles the unit cell of the simple undistorted $A M X_{3}$ perovskite, changing the space-group symmetry from $P m \overline{3} m$ to $F m \overline{3} m$. Just as with $A M X_{3}$ perovskites, several distortion mechanisms are observed in ordered double perovskites. An octahedral tilting distortion occurs when the $A$-site cation is too small for the cubo-octahedral cavity of the corner-sharing octahedral network. Notations to describe various types of octahedral tilting distortions were developed independently by Aleksandrov (1976) and Glazer (1972). Throughout this text we will use the notation of Glazer. Both octahedral tilting distortions and the formation of an ordered cation arrangement induce a change of the unit-cell size and space-group symmetry. The reader is referred elsewhere for a more complete description of the space-group symmetries and unitcell sizes of perovskites resulting from a combination of octahedral tilting and $M$-site cation ordering (Aleksandrov \& Misyul, 1981; Woodward, 1997a; Bock \& Müller, 2002; Howard et al., 2003; Howard \& Stokes, 2004, 2005).

As was shown in the preceding article and discussed previously in the literature (Howard et al., 2003), cation ordering makes the task of identifying out-of-phase tilting more difficult. Therefore, the possibility of incorrect spacegroup assignment is even higher among ordered perovskites than it is among ternary perovskites. Increased structural complexity in double perovskites leads to more degrees of freedom, thus increasing the number of variables and making the structure solution and refinement process more difficult (particularly when pseudosymmetry is severe). In order to obtain the correct crystal structure, good starting models are needed for structural refinements. This argument provided the motivation to expand the capabilities of the software program SPuDS (Lufaso \& Woodward, 2001), which previously was able to model $A M X_{3}$ and $A_{1-x} A_{x}^{\prime} M X_{3}$ perovskites only, to handle ordered double perovskites. Modeling capabilities have been extended to calculate optimized crystal structures in the most commonly observed space groups for rock-salt ordered double perovskites: $F m \overline{3} m\left(a^{0} a^{0} a^{0}\right), I 4 / m\left(a^{0} a^{0} c^{-}\right)$, P4/mnc $\left(a^{0} a^{0} c^{+}\right), R \overline{3}\left(a^{-} a^{-} a^{-}\right), I 2 / m\left(a^{0} b^{-} b^{-}\right), \operatorname{Pn} \overline{3}\left(a^{+} a^{+} a^{+}\right)$ and $P 2_{1} / n\left(a^{-} a^{-} b^{+}\right)$.

It is anticipated that the capability to predict the crystal structures of ordered double perovskites will find a number of uses. Physical properties can be estimated from SPuDSgenerated structures using computational tools for hypothetical compositions or those compounds where reliable structural data are not available. SPuDS can be used as a guide for exploratory synthetic efforts by quickly finding ion combinations that can adopt the perovskite topology with minimal bond strains. The structures generated by $S P U D S$ possess perfectly regular octahedra, whereas in real crystals this is often not strictly true. Therefore, comparisons between the observed and calculated structures enable one to deconvolute the effects of octahedral tilting from other distortion mechanisms. A nice illustration of this process can be found in the recent paper by Zhou \& Goodenough (2005). Finally, $S P U D S$ provides excellent starting models for use in Rietveld refinements, allowing one to test easily a variety of tilt systems for agreement with the experimental data. This application may help to reduce the number of erroneous structure reports that, unfortunately, are fairly common in the perovskite literature.

\section{Survey of octahedral tilting in ordered double perovskites}

The space-group symmetry, degrees of freedom, number of Wyckoff sites per ion and the frequency of literature reports for each tilt system are shown in Table 1 . The tilt systems have been subdivided into two categories: group $A$, where all $A$-site cations are crystallographically equivalent, and group $B$, where the $A$-site cations occupy multiple crystallographic sites. It has been shown in $A M X_{3}$ perovskites that tilt systems belonging to group $A$ are strongly preferred over those belonging to group $B$, except in cases where ions with distinctly different sizes occupy the $A$ site $\left(\right.$ e.g. $\mathrm{CaCu}_{3} \mathrm{Ti}_{4} \mathrm{O}_{12}$; Woodward, 1997c). Table 1 shows that a similar trend holds for ordered perovskites. In fact, it is only recently that ordered perovskites belonging to group $B$ have been reported (Byeon et al., 2003, 2004).

While it is true that, in general, the preferred tilt systems of ordered $A_{2} M M^{\prime} X_{6}$ and $A_{2-x} A_{x}^{\prime} M M^{\prime} X_{6}$ perovskites are 
similar to the preferences of $A M X_{3}$ and $A_{1-x} A_{x}^{\prime} M X_{3}$ perovskites, there are some differences. Among ordered double perovskites the undistorted aristotype cubic structure accounts for $\sim 30 \%$ of the reported structures for oxides and almost all of the halides. In contrast, less than $\sim 10 \%$ of $A M X_{3}$ perovskites adopt the undistorted cubic structure at room temperature and pressure. The rhombohedral $a^{-} a^{-} a^{-}$tilt system is more common among $A M X_{3}$ perovskites, whereas the tetragonal $a^{0} a^{0} c^{-}$tilt system is more prevalent among ordered perovskites. There are numerous examples of $a^{+} a^{+} a^{+}$ tilting among $A^{\prime} A_{3} M_{4} X_{12}$ compositions but few analogues amongst $A^{\prime} A_{3} M_{2} M_{2}^{\prime} X_{12}$ ordered perovskites. These differences between ordered double perovskites and simple perovskites are investigated in more detail in $\S 4$.

\section{Experimental - SPuDS calculation method}

The algorithm utilized in the SPuDS crystal structure calculations has been described previously (Lufaso \& Woodward, 2001). Therefore, our discussion is limited to a brief overview and a summary of new features. Unconstrained optimization of the crystal structure requires determination of the unit-cell dimensions and all free positional parameters. The number of variables to be optimized depends on the tilt system and varies from two to 18 (see Table 1). Most distorted ordered double perovskites show minimal distortions of the $\left[M X_{6}\right]$ and $\left[M^{\prime} X_{6}\right]$ octahedra, unless there is an electronic (e.g. Jahn-Teller $M$-site cation) or structural (e.g. oversized $A$-site cation) driving force that favors a distortion. For this reason the calculations are based on the tilting of rigid octahedra. The full crystal structure is calculated from the $M-X$ and $M^{\prime}-X$ bond distances, the tilt angle, and the free positional parameters of the $A$-site cation. The $M-X$ and $M^{\prime}-X$ bond distances that determine the sizes of the octahedra are calculated using the bondvalence method (Brown, 1978; Brese \& O'Keeffe, 1991; http:// www.ccp14.ac.uk/ccp/web-mirrors/i_d_brown, accessed April 2005) by constraining the $M$ and $M^{\prime}$ bond-valence sums to equal their formal oxidation states. ${ }^{1}$ For each tilt system the space group, unit-cell basis vectors and occupied Wyckoff sites are used as previously reported (Howard et al., 2003). The $M$ and $M^{\prime}$ cations remain on fixed positions in all space groups that result from cation ordering and octahedral tilting. Equations describing the lattice parameters and fractional coordinates of the $X$ anion in terms of the $M-X$ and $M^{\prime}-X$ bond lengths and the tilt angle(s) are derived from geometric principles using matrix algebra methods. The octahedral tilting is described using the notation where $a^{0} a^{0} c^{-}$tilting corresponds to a single tilt $\varphi$ about the cubic [001] direction, $a^{0} b^{-} b^{-}$ tilting corresponds to a single tilt $\theta$ about the cubic [011] direction, and $a^{-} a^{-} a^{-}$tilting corresponds to a single tilt $\Phi$ about the cubic [111] direction (Zhao et al., 1993). Owing to the symmetry breaking that occurs as a result of incorporating

\footnotetext{
${ }^{1}$ Postulated bond-valence parameters, $R_{i j}$, included in SPuDS that are not included in the tabulation by Brown (http://www.ccp14.ac.uk/ccp/web-mirrors/ i_d_brown $)$ are $R\left(\mathrm{Ir}^{6+}-\mathrm{O}^{2-}\right)=1.908, R\left(\mathrm{Os}^{5+}-\mathrm{O}^{2-}\right)=1.890, R\left(\mathrm{Os}^{7+}-\mathrm{O}^{2-}\right)=$ $1.952, R\left(\mathrm{Pr}^{4+}-\mathrm{O}^{2-}\right)=2.077, R\left(\mathrm{Re}^{6+}-\mathrm{O}^{2-}\right)=1.949, R\left(\mathrm{Rh}^{4+}-\mathrm{O}^{2-}\right)=1.8$ and $R\left(\mathrm{~Tb}^{4+}-\mathrm{O}^{2-}\right)=1.997$ with $b=0.37$.
}

octahedra of two different sizes, the equations that describe the lattice parameters and anionic positions are somewhat more complicated than the equations that hold for $A M X_{3}$ and $A_{1-x} A_{x}^{\prime} M X_{3}$ perovskites. The reader is referred elsewhere for a derivation of complete equations used for each tilt system (Lufaso, 2002).

The $S P u D S$ output file contains a complete crystallographic description of the compound in question and more, including the space group, lattice parameters, atomic coordinates, ${ }^{2}$ bond-valence sums, individual bond valences and distances, tolerance factor, ${ }^{3}$ unit-cell volume, octahedral tilt angles, $M-$ $X-M^{\prime}$ bond angles, and global instability index (GII) (Salinas-Sanchez et al., 1992). Optimized GII values are reported for all seven tilt systems that are investigated in $S P U D S$. These values can be used to evaluate the relative stability of each tilt system. Typically GII values are less than 0.1 v.u. (valence units) for unstrained structures and as large as 0.2 v.u. in a structure with lattice-induced strains. Reported crystal structures with GII values greater than 0.2 v.u. are typically unstable and are often found to be erroneous (Rao et al., 1998). The octahedral tilt angles for experimental crystal structures are calculated using TUBERS, which is a companion software program for SPUDS. TUBERS calculates an average octahedral tilt angle (or angles) based on the reported crystal structure. In order to simplify the comparison of experimental and calculated crystal structures the experimental crystal structures were converted to have the same setting and approximate atomic positions as the crystal structure output by $S P U D S$.

\section{Results and discussion}

\section{1. $F m \overline{3} m\left(a^{0} a^{0} a^{0}\right)$}

The undistorted aristotype $A_{2} M M^{\prime} X_{6}$ rock-salt ordered perovskite structure has $F m \overline{3} m$ space-group symmetry, $Z=4$ and only two degrees of freedom: the lattice parameter or cell edge, and the $x$ coordinate of the anion. The fractional positions are $A\left(\frac{1}{4}, \frac{1}{4}, \frac{1}{4}\right), M(0,0,0), M^{\prime}\left(\frac{1}{2}, \frac{1}{2}, \frac{1}{2}\right)$ and $X(x, 0,0)$ with $x \simeq \frac{1}{4}$. Untilted perovskites are assigned to the $a^{0} a^{0} a^{0}$ tilt system. Table 2 contains a list of oxides that have been reported to adopt this tilt system. These compounds are taken largely from the ICSD and are sorted in order of decreasing tolerance factor. The ICSD contains an additional 66 examples of fluorides, ten examples of oxyfluorides and 18 examples of heavier halides with the $F m \overline{3} m$ structure. Among oxides that adopt this structure at room temperature and pressure one can find tolerance factors ranging from $\sim 1.05$ for compounds such as $\mathrm{Ba}_{2} \mathrm{NiMoO}_{6}$ (Martinez-Lope et al., 2003) and $\mathrm{Ba}_{2} \mathrm{FeNbO}_{6}$ (Tezuka et al., 2000) to $\sim 0.98$ for compounds such as $\mathrm{Ba}_{2} \mathrm{YNbO}_{6}$ (Barnes et al., 2006) and $\mathrm{Ba}_{2} \mathrm{HoSbO}_{6}$ (Alonso et al., 1997). Ordered $A_{2} M M^{\prime} X_{6}$ perovskites that belong to the $a^{0} a^{0} a^{0}$ tilt system are both more numerous and span a wider

\footnotetext{
${ }^{2}$ Lattice parameters are reported to the nearest $0.0001 \AA$ and $0.01^{\circ}$. The fractional coordinates are reported to the nearest 0.001 .

${ }^{3}$ The tolerance factor, $\tau$ (Goldschmidt, 1926), describes the fit of the $A$-site cation in the cavity formed by the corner-sharing octahedra and may be used to estimate the occurrence and magnitude of the octahedral tilting distortion.
} 
Table 2

Lattice parameters and oxygen positional parameter, $x$, as experimentally observed and as calculated by $\operatorname{SPuDS}$ (GII optimized) for $a^{0} a^{0} a^{0}(F m \overline{3} m)$ perovskites.

The $M$-site cation listed first in the formula is located at the origin $(0,0,0)$ and the second is at $\left(\frac{1}{2}, 0,0\right)$. Method abbreviations are XRPD $=\mathrm{X}$-ray powder diffraction, $\mathrm{XRSD}=\mathrm{X}$-ray single crystal diffraction, and SXRPD = synchrotron X-ray powder diffraction.

\begin{tabular}{|c|c|c|c|c|c|c|c|}
\hline \multirow[b]{2}{*}{ Formula } & \multirow[b]{2}{*}{$\tau$} & \multirow[b]{2}{*}{ Method } & \multicolumn{2}{|l|}{ Observed } & \multicolumn{2}{|l|}{ SPuDS } & \multirow[b]{2}{*}{ Ref. } \\
\hline & & & $a(\AA)$ & $x$ & $(\AA)$ & $x$ & \\
\hline & 1.074 & $D$ & & & 658 & & \\
\hline & 1.051 & NPD & & & & & \\
\hline $\mathrm{O}_{6}$ & 1.044 & 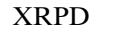 & & & & & \\
\hline $\mathrm{a}_{2} \mathrm{CoMoO}_{6}$ & 1.041 & PD & & & 1950 & 200 & \\
\hline - CoWO & 1.038 & NPD & & & 2110 & 200 & \\
\hline & 1.038 & & & & & & \\
\hline & 1.030 & & & & & & $(f)$ \\
\hline & 1.028 & & & & & & \\
\hline & 1.020 & XRPD & & & 7788 & & h) \\
\hline & 1.019 & & & & 538 & 0 & \\
\hline & & & & & & & \\
\hline & & & & & & & i) \\
\hline$O_{-}$ & 1.014 & & & & & & 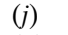 \\
\hline & & & & & 078 & & h) \\
\hline & & & & & & & \\
\hline & & & & & & & \\
\hline & & & & & & & \\
\hline $\mathrm{ChO}$ & 0.995 & & & & 78 & & n) \\
\hline & & & & & & & $1)$ \\
\hline & 4 & & & & & & ) \\
\hline & & & & & & & q) \\
\hline & & & & & & & 7 \\
\hline 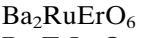 & 0.990 & & & & 78 & 4 & ( \\
\hline & & & & & & & 1 \\
\hline & & & & & 78 & & \\
\hline & & & & & & & \\
\hline & 0.985 & & & & 4178 & & (h) \\
\hline & & & & & 258 & 0.268 & $(v)$ \\
\hline & & & & & & & \\
\hline & & & & & 38 & 0.2 & \\
\hline & & & & & 138 & 烈 & \\
\hline & 0.977 & RP & & (2) & 8.4618 & 0.264 & (w) \\
\hline & 0.977 & & & & 8.4658 & 0.264 & \\
\hline & & & & & & & \\
\hline & & & & & & & \\
\hline & & & & & & & \\
\hline $\mathrm{Ba}_{2} \mathrm{SmSbO}_{6}$ & 0.958 & XRPD & $8.50908(8)$ & $0.258(2)$ & 8.5878 & 0.268 & $(d d)$ \\
\hline
\end{tabular}

References: (a) Stitzer et al. (2002), (b) Martinez-Lope et al. (2003), (c) Tezuka et al. (2000), (d) Martinez-Lope et al. (2002), (e) Patwe et al. (2005), ( $f$ ) Nguyen et al. (2002), (g) Rammeh et al. (2004), (h) Woodward (1997b), (i) Ouchetto et al. (1991), (j) Azad et al. (2001), (k) Amador et al. (1992), (l) Dianoux \& Poix (1968), ( $m$ ) Baldinozzi et al. (1998), (n) Doi et al. (2003), (o) Battle \& Jones (1989), (p) Arulraj et al. (2000), (q) Choy et al. (1996), (r) Taira \& Hinatsu (2000), (s) Izumiyama et al. (2002), (t) Doi \& Hinatsu (2001), (u) Doi et al. (2003), (v) Battle \& Jones (1989), (w) Grenet et al. (1972), (x) Hinatsu et al. (2004), (y) Barnes et al. (2006), (z) Karunadasa et al. (2003), (aa) Fu \& Ijdo (1997), (bb) Jung et al. (1993), (cc) Alonso et al. (1997), (dd) Fu \& Ijdo (2005b).

range of tolerance factors than their $A M X_{3}$ counterparts. The enhanced stability of the undistorted cubic structure among ordered perovskites can be understood, in part, by considering the forces that favor second-order Jahn-Teller (SOJT) distortions of the octahedral site cations (Halasyamani \& Poeppelmeier, 1998; Halasyamani, 2004). Classic examples of this include $\mathrm{BaTiO}_{3}(\tau=1.06)$ (Kwei et al., 1993) and $\mathrm{KNbO}_{3}$ ( $\tau=1.06$; Hewat, 1973), both of which undergo a series of symmetry-lowering phase transitions upon cooling, which involve displacements of the $M$-site cations. Strong covalent bonding between the $d^{0}$ transition metal ion and oxygen drives these displacements. In the case of $\mathrm{BaTiO}_{3}$ the oversized $\mathrm{Ba}^{2+}$ ion places the $\mathrm{Ti}-\mathrm{O}$ bonds under tension, thereby inducing the titanium displacements. Similar distortions do not occur in the $A \mathrm{TiO}_{3}$ series when the $A$-site cation is the right size, as is the case with $\mathrm{SrTiO}_{3}$ ( $\tau=1.00$; Hutton et al., 1981), or too small, as is the case with $\mathrm{CaTiO}_{3}(\tau=0.95$; Sasaki et al., 1987). In contrast, niobium displacements persist in $\mathrm{NaNbO}_{3}(\tau=$ 0.97; Sakowski-Cowley et al., 1969) and are also present in $\mathrm{WO}_{3}$ (Howard et al., 2002; Woodward et al., 1997), where there is no $A$-site cation at all. The metal-oxygen covalency in these two compounds is sufficiently high that the occurrence of SOJT distortions is not dependent upon bond strains introduced by the $A$-site cation.

SOJT distortions involving the octahedral cations are much less common in ordered perovskites, increasing the population of the $a^{0} a^{0} a^{0}$ tilt system among $A_{2} M M^{\prime} X_{6}$ perovskites when $\tau>$ 1. The paucity of octahedral site SOJT distortions among ordered perovskites can be understood by considering the bonding at the $\mathrm{O}$ atoms. As an example, consider the bonding in the tetragonal form of $\mathrm{KNbO}_{3}$. The niobium ion displaces toward the oxygen ion that lies immediately above it, producing a short $\mathrm{Nb}-\mathrm{O}$ bond. This distortion leads to an overbonding at the oxygen site that is compensated for by a parallel displacement of the niobium ion in the neighboring octahedron away from the oxygen. This type of cooperative displacement creates one short and one long $\mathrm{Nb}-\mathrm{O}$ bond, thereby maintaining a reasonable bond valence for oxygen. In an ordered double perovskite, such as $\mathrm{Ba}_{2} \mathrm{MgWO}_{6}$, typically only one of the octahedral site cations has the proper electron configuration $\left(d^{0}\right)$ to favor a SOJT distortion. As a consequence, if the $\mathrm{W}^{6+}$ ion displaces to form a short $\mathrm{W}-\mathrm{O}$ bond, the overbonding at oxygen cannot be relieved because the neighboring $\mathrm{Mg}^{2+}$ cation is not prone to displace and create the long $\mathrm{Mg}-\mathrm{O}$ bond needed to maintain an appropriate bonding interaction at oxygen. This situation effectively destroys the cooperativity of the $\mathrm{W}^{6+}$ displacements and dampens the soft modes associated with displacements of these ions. Ferroelectric or antiferroelectric type displacements of $d^{0}$ transition metal ions on the octahedral site in ordered double perovskites typically occur only through coupling with lone-pair cations, which are also SOJT active, on the $A$-site. Examples include $\mathrm{Pb}_{2} \mathrm{MgWO}_{6}$ (Baldinozzi et al., 1995) and $\mathrm{Pb}_{2} \mathrm{ScTaO}_{6}$ (Woodward \& Baba-Kishi, 2002).

While SOJT distortions are not common in ordered perovskites, there is no doubt that the $M-X$ and $M^{\prime}-X$ bonds are placed under tension when $\tau>1$. In order to model accurately the crystal structures of $a^{0} a^{0} a^{0}$ double perovskites, two calculation schemes were developed. The standard calculation method fixes the $M-X$ and $M^{\prime}-X$ bond distances at the beginning of the process, thereby fixing both degrees of freedom and leaving the $A$-site cation overbonded. This shortcoming led us to introduce a second calculation method that takes into account these competing bond strains. The lattice parameter and fractional coordinate of the anion are first calculated in the standard manner. The lattice parameter is then varied until the GII reaches a minimum value. As a quantitative comparison of these two approaches consider the 


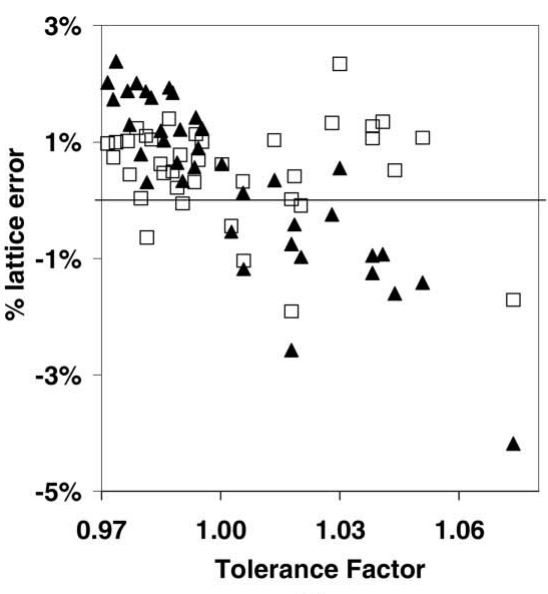

(a)

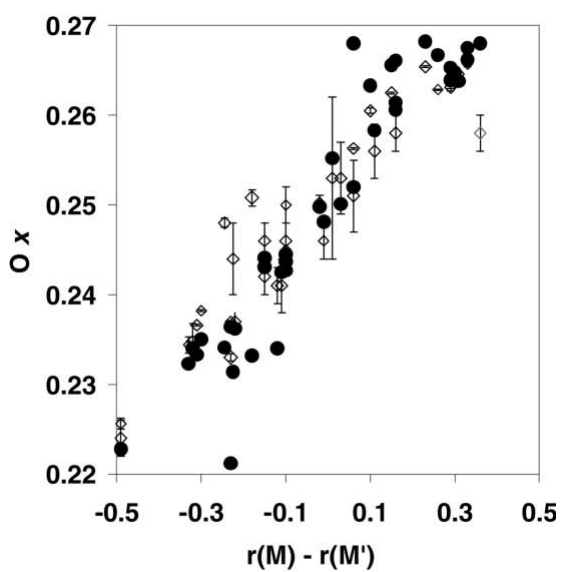

(b)

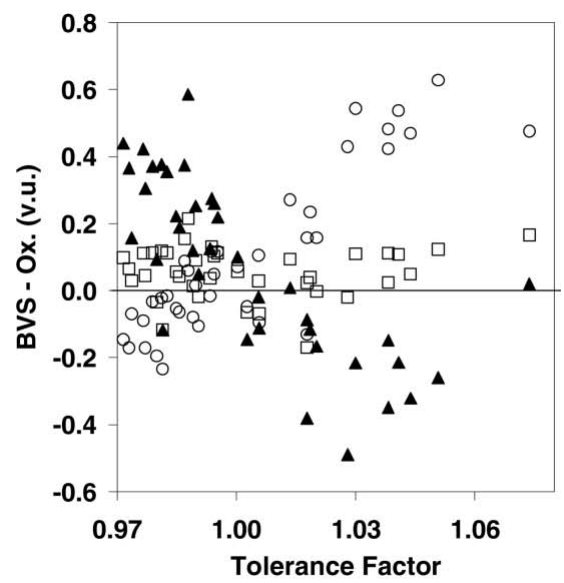

(c)

Figure 1

(a) Percent lattice error for fixed $M-X$ and $M^{\prime}-X$ and GII optimized structures versus tolerance factor for tilt system $a^{0} a^{0} a^{0}(F m \overline{3} m)$. Percent lattice error is defined as $\left[\left(a_{\mathrm{s}}-a_{\mathrm{obs}}\right) / a_{\mathrm{s}}\right] \times 100$, where $a_{\mathrm{s}}$ and $a_{\text {obs }}$ are the $S P U D S$ predicted and experimentally observed lattice parameters, respectively. Open squares represent the GII and filled triangles represent fixed $M-X$ and $M^{\prime}-X$ optimized crystal structures. $(b)$ Oxygen fractional coordinate $x$ versus $r(M)-r\left(M^{\prime}\right)$, where $r(M)$ is the radius of the $M$ cation at the origin and $r\left(M^{\prime}\right)$ is the radius of the $M^{\prime}$ cation at $\left(\frac{1}{2}, 0,0\right)$. Open diamonds represent observed values and filled circles represent the predicted value. (c) Bond-valence sum minus the formal oxidation state for the experimental crystal structures versus tolerance factor. Circles represent the $A$ cation, filled triangles the average $M$ cation and squares the $\mathrm{O}$ atom. agreement between the calculated and observed values of the lattice parameter, as illustrated in Fig. 1(a). Not surprisingly the first calculation method (filled triangles) overestimates the lattice parameter when $\tau<1$ and underestimates the lattice parameter when $\tau>1$, because the role of the $A$-site cation is completely neglected. A more accurate prediction of the lattice parameter was obtained by allowing the octahedral bond distances to vary, particularly in the calculation of the lattice parameters for structures with $\tau<1$. Using this latter method the error in the lattice parameter is typically less than $1.5 \%$. Fig. 1(b) shows the calculated and observed values of the anion coordinate $x$ as a function of the difference in the ionic radii of octahedral site cations, $r(M)-r\left(M^{\prime}\right)$. Here the agreement between calculation and experiment is even better. Finally, Fig. 1(c) shows the deviation of the bond-valence sum for each ion from its formal oxidation state. The trends are pretty much as expected. When $\tau<1$, the $A$-site cation is underbonded and the octahedral site cations are overbonded, whereas with $\tau>1$, the opposite trends are observed. It is interesting and perhaps not intuitive to note that regardless of tolerance factor the $\mathrm{O}$ atom retains a bond-valence sum that shows little deviation from its ideal value of 2 . Once again the sometimes neglected bonding preferences of the anion are seen to be critical in directing structure.

\section{2. $14 / m\left(a^{0} a^{0} c^{-}\right)$and P4/mnc $\left(a^{0} a^{0} c^{+}\right)$}

Imposition of a single rotation of the octahedra about one of the fourfold axes destroys the threefold axes and the perpendicular fourfold axes, lowering the symmetry to tetragonal. Out-of-phase rotations of the octahedra, $a^{0} a^{0} c^{-}$, lead to a structure with $I 4 / m$ symmetry, while in-phase rotations of the octahedra, $a^{0} a^{0} c^{+}$, lead to a structure with $P 4 / m n c$ symmetry. Only one double perovskite system, $\mathrm{Ba}_{2-x} \operatorname{PrRu}_{1-x} \mathrm{Ir}_{x} \mathrm{O}_{6}$ $(0.4<x<1.0)$, has been reported to crystallize with the $P 4 / m n c$ structure (Li \& Kennedy, 2004). It is worth mentioning that $\mathrm{Ba}_{2} \mathrm{PrIrO}_{6}$ was subsequently reported to crystallize in space group $F m \overline{3} m$ (Fu \& Ijdo, 2005a). The fractional positions in the structure with $P 4 / m n c$ symmetry are $A\left(0, \frac{1}{2}, \frac{1}{4}\right), M$ $(0,0,0), M^{\prime}\left(\frac{1}{2}, \frac{1}{2}, 0\right)$ and $X 1(0,0, z)$ with $z \simeq \frac{1}{4}$, and $X 2(x, y, 0)$ with $x \simeq \frac{1}{4}$ and $y \simeq \frac{3}{4}$.

The $I 4 / m\left(a^{0} a^{0} c^{-}\right)$structure is the much more common variety of tetragonal ordered double perovskite. The fractional positions are $A\left(0, \frac{1}{2}, \frac{1}{4}\right), M(0,0,0), M^{\prime}\left(\frac{1}{2}, \frac{1}{2}, 0\right), X 1(0,0$, $z$ ) with $z \simeq \frac{1}{4}$, and $X 2(x, y, 0)$ with $x \simeq \frac{1}{4}$ and $y \simeq \frac{1}{4}$. Table 3 lists examples of $A_{2} M M^{\prime} X_{6}$ perovskites and compares the structural parameters predicted by $S P U D S$ with the reported values. $\mathrm{Ba}_{2} \mathrm{CuTeO}_{6}$ and $\mathrm{Ba}_{2} \mathrm{CuWO}_{6}$ and the analogous $A=\mathrm{Sr}$ compounds stand out from the rest of the entries because $(a)$ they have large tolerance factors and $(b)$ the value of $2^{1 / 2} a / c$ is much smaller than predicted by $S P U D S$. The latter trend can easily be understood by recognizing that the octahedron surrounding the $\mathrm{Cu}^{2+}$ ion will undergo a large axial elongation owing to a first-order Jahn-Teller distortion (Lufaso \& Woodward, 2004). Even without octahedral tilting, the JahnTeller distortion will lower the symmetry from cubic to tetragonal. It seems likely that the primary distortion 
Table 3

Experimental and SPUDS predicted lattice parameters and free fractional coordinates for selected $P 4 / m n c$ (top) and $I 4 / m$ (bottom) perovskites.

The $M$-site cation listed first in the formula is located at the origin $(0,0,0)$ and the second is at $\left(\frac{1}{2}, \frac{1}{2}, 0\right)$.

\begin{tabular}{|c|c|c|c|c|c|c|c|c|}
\hline Formula & $\tau$ & Method & $a(\AA)$ & $c(\AA)$ & $\mathrm{O}(4 e) z$ & $\mathrm{O}(8 h) x$ & $\mathrm{O}(8 h) y$ & \\
\hline $\mathrm{Ba}_{2} \mathrm{PrIrO}_{6}$ & 0.982 & XRPD & $5.9395(1)$ & 8.4007 (2) & $262(4)$ & $43(2)$ & $.716(3)$ & (a) \\
\hline ormula & $\tau$ & Source & $a(\AA)$ & (A) & $z$ & $\mathrm{O}(8 h) x$ & $\mathrm{O}(8 h) y$ & \\
\hline \multirow[t]{2}{*}{$\mathrm{Ba}_{2} \mathrm{CuTeO}_{6}$} & \multirow[t]{2}{*}{1.042} & XRPD & $5.5903(1)$ & $8.6426(3)$ & 0.281 & 0.263 & 0.244 & \multirow[t]{2}{*}{$(b)$} \\
\hline & & SPuDS & 5.6604 & 8.0 & 0.2 & 1 & 0.2 & \\
\hline \multirow{2}{*}{$\mathrm{Ba}_{2} \mathrm{WCuO}_{6}$} & \multirow[t]{2}{*}{1.042} & XRPD & 8) & 8.6274 & $0.2293(17)$ & $0.2902(25)$ & 0.1965 (33) & \multirow[t]{2}{*}{$(c)$} \\
\hline & & SPuDS & 5.6604 & 8.0050 & 0.240 & 0.240 & 0.240 & \\
\hline \multirow{2}{*}{$\mathrm{Sr}_{2} \mathrm{MoNiO}_{6}$} & \multirow[t]{2}{*}{0.991} & NPD & $39(5)$ & $54(9)$ & $6(6)$ & $87(5)$ & 39 (4) & \multirow[t]{2}{*}{$(d)$} \\
\hline & & SPuD & & 7.9350 & & & & \\
\hline \multirow[t]{2}{*}{$\mathrm{Sr}_{2} \mathrm{CrTaO}_{6}$} & \multirow[t]{2}{*}{0.991} & NPD & ) & 7.8808 & 0.2501 & $0.2342(8)$ & $0.2655(6)$ & \multirow[t]{2}{*}{ (e) } \\
\hline & & SPuD & & & & & & \\
\hline \multirow{2}{*}{$\mathrm{Sr}_{2} \mathrm{GaTaO}_{6}$} & \multirow[t]{2}{*}{0.990} & NPD & 1) & 7.89 & $9(7)$ & $27(5)$ & 5) & \multirow[t]{2}{*}{$(e)$} \\
\hline & & SPuDs & & 7.9478 & 0.250 & 223 & 0.277 & \\
\hline \multirow[t]{2}{*}{$\mathrm{Sr}_{2} \mathrm{WNiO}_{6}$} & \multirow[t]{2}{*}{0.989} & XRP & & & & & 2) & \multirow[t]{2}{*}{$(f)$} \\
\hline & & & & & & & & \\
\hline \multirow{2}{*}{$\mathrm{Sr}_{2} \mathrm{VTaO}_{6}$} & \multirow[t]{2}{*}{0.986} & XRPI & & & & 5) & $4(5)$ & \multirow[t]{2}{*}{ (g) } \\
\hline & & SPuD & 5 & 7.9 & 0.251 & 210 & (28 & \\
\hline \multirow[t]{2}{*}{$\mathrm{Sr}_{2} \mathrm{FeMoO}_{6}$} & \multirow{2}{*}{0.986} & NPD & $8(2)$ & $61(8)$ & $28(9)$ & $0.2378(5)$ & $0.2658(6)$ & (h) \\
\hline & & & & & & & & \\
\hline${ }_{2} \mathrm{FeNbO}_{6}$ & 0.985 & XR & & & & (9) & $7(7)$ & (i) \\
\hline & & & & & & & & \\
\hline${ }_{2} \mathrm{GaSbO}_{6}$ & 0.984 & NPD & $1(9)$ & 7.9 & $33(4)$ & $0.2241(4)$ & $0.2770(4)$ & (j) \\
\hline & & & & & & & & \\
\hline $\mathrm{CuTeO}_{6}$ & 0.983 & $\mathrm{~N}$ & & & 0 . & 0.2098 & $3(3)$ & $(k)$ \\
\hline & & & & & & 0225 & 0.2 & \\
\hline${ }_{2} \mathrm{WCuO}_{6}$ & 0.983 & XRP & 5) & 8.40 & $0.2235(12)$ & $0.2027(21)$ & 0.2948 (17) & $(l)$ \\
\hline & & SPuD & & 8.00 & & 0.203 & & \\
\hline $\mathrm{Sr}_{2} \mathrm{CoMoO}_{6}$ & 0.982 & NPD & 5. & 7.9 & 0.2589 & 0.2296 & 0.2895 (3) & $(r$ \\
\hline & & & & & & & & \\
\hline${ }_{2} \mathrm{WCoO}_{6}$ & 0.979 & $\mathrm{XRP}$ & 5 & 7.9 & 0.238 (1) & $1(1)$ & $0.274(1)$ & $(f)$ \\
\hline & & & & & & & 0.2 & \\
\hline $\mathrm{Sr}_{2} \mathrm{WMgO}_{6}$ & 0.979 & XRPD & $5.5817(1)$ & 7.990 (1) & 0.235 (1) & 0.209 (1) & 0.270 & $(n)$ \\
\hline & & & & & & & & \\
\hline${ }_{2} \mathrm{WZnO}_{6}$ & 0.977 & XRPD, 3 & 5.59 & 7.9 & 0.2 & 0.2 & $0.292(2)$ & $(f$ \\
\hline & & & & & & & & \\
\hline $\mathrm{r}_{2} \mathrm{ReMgO}_{6}$ & 0.971 & $\mathrm{NH}$ & & 7.9 & $0.242(1)$ & $0.2066(7)$ & $0.2700(9)$ & $(o)$ \\
\hline & & SPuDS & 5.6276 & 8.0970 & 0.241 & 0.194 & 0.287 & \\
\hline
\end{tabular}

References: (a) Li \& Kennedy (2004), (b) Iwanaga et al. (1999), (c) Bokhimi (1992), (d) Martinez-Lope et al. (2003), (e) Barnes et al. (2006), (f) Gateshki et al. (2003), (g) Woodward (1997b), (h) Chmaissem et al. (2000), (i) Tao et al. (2004), (j) Barnes (2003), (k) Reinen \& Weitzel (1976), (l) Bokhimi (1992), (m) Viola et al. (2002), ( $n$ ) Gateshki \& Igartua (2004), (o) Wiebe et al. (2003).

mechanism in these compounds is the Jahn-Teller distortion, and the out-of-phase octahedral tilts are a secondary distortion mechanism. This fact helps to explain why the tolerance factors of these compounds deviate from the rest of the examples in Table 3. Excluding compounds that contain a Jahn-Teller ion $\left(\mathrm{Cu}^{2+}\right.$ or $\left.\mathrm{Mn}^{3+}\right)$ on one of the octahedral sites, there are two commonalities among the oxides that adopt the $I 4 / m$ structure. First, the tolerance factors of these compounds fall over a fairly narrow range, roughly from 0.99 to 0.97 . Secondly, the $A$-site cation is $\mathrm{Sr}^{2+}$ in the vast majority of cases. Of course, these two observations are not entirely independent of each other, but it is worth noting that a number of examples of $\mathrm{Ba}_{2} M M^{\prime} \mathrm{O}_{6}$ compounds with tolerance factors in the range 1.00-0.97 can be found among the cubic perovskites in Table 2.
The accuracy of the structural parameters predicted by $S P U D S$ in Table 3 is reasonably good, but there are some common trends in the discrepancy between observed and calculated values. These trends can be seen more easily when the data are displayed graphically. The observed and calculated values of the $M-$ $\mathrm{O}-M^{\prime}$ bond angles in the $x y$ plane are shown in Fig. 2(a). As expected, the octahedral tilt angle smoothly increases as the tolerance factor decreases in both the calculated and the observed structures. The octahedral tilt angle is consistently predicted to be $\sim 2.5^{\circ}$ larger than observed, although admittedly there are a number of points that do not obey this relationship. The observed and calculated values of the $c /\left(2^{1 / 2} a\right)$ ratio, which is a measure of the tetragonal distortion, are plotted in Fig. 2(b). As $\tau$ decreases the octahedral tilting increases causing the $a$ axis to contract and the $c /\left(2^{1 / 2} a\right)$ ratio to increase. Once again the calculations and observations follow the same trend, but the calculations consistently overestimate the $c /\left(2^{1 / 2} a\right)$ ratio. This can be traced in part to the overestimation of the octahedral tilting. The dashed line in Fig. 2(b) shows what the $c /\left(2^{1 / 2} a\right)$ ratio would be if the octahedral tilt angle was smaller by $2.5^{\circ}$ but the octahedra remained perfectly regular.

Finally we should note that the minimum GII value that can be obtained with either the $a^{0} a^{0} c^{-}$or the $a^{0} a^{0} c^{+}$tilt system is somewhat higher than the minimum GII value that can be obtained assuming $a^{-} a^{-} a^{-}$or $a^{-} a^{-} b^{+}$tilting. Clearly the GII cannot be used blindly to predict the most stable tilt system, particularly when the octahedral tilting distortion is fairly small. In such cases additional factors need to be taken into account to determine the most stable structure. Furthermore, most perovskites that have tolerance factors that are a slightly smaller than unity undergo transitions to other tilt systems as a function of temperature. Thus, the energetic differences between competing tilt systems are necessarily small.

\section{3. $I 2 / m\left(a^{0} b^{-} b^{-}\right)$}

The combination of two out-of-phase tilts of equal magnitude about the $a$ and $b$ axes of the cubic cell, tilt system $a^{0} b^{-} b^{-}$, is the equivalent of a single tilt, $\theta$, about the [011] direction of the aristotype structure. The combination of rocksalt cation ordering and $a^{0} b^{-} b^{-}$tilting produces a structure 
with $I 2 / m$ space-group symmetry. The fractional positions are $A(x, 0, z)$ with $x \simeq \frac{1}{2}$ and $z \simeq \frac{1}{4}, M(0,0,0), M^{\prime}\left(\frac{1}{2}, \frac{1}{2}, 0\right), X 1(x, 0$, z) with $x \simeq 0$ and $z \simeq \frac{1}{4}$, and $X 2(x, y, z)$ with $x \simeq \frac{1}{4}, y \simeq \frac{1}{4}$ and $z \simeq$ 0 . There are relatively few reported examples of $a^{0} b^{-} b^{-}$ ordered perovskites. Oxide examples are listed in Table 4, together with a comparison of the calculated and reported values of key structural variables. Recently, $\mathrm{Sr}_{2} \mathrm{CoTeO}_{6}$ was suggested to undergo a phase transition from space group $P 2_{1} / n$ to $I 2 / m$ to $F m \overline{3} m$ at 373 and $773 \mathrm{~K}$, respectively; however, complete crystal structures were not reported (Ortega-San Martin et al., 2005). It is interesting to note that many of the compounds in Table 4 contain a main group ion in a high oxidation state $\left(\mathrm{Bi}^{5+}, \mathrm{Sb}^{5+}\right.$ and $\left.\mathrm{Te}^{6+}\right)$. This situation is in contrast to members of the $a^{0} a^{0} c^{-}$tilt system where transition

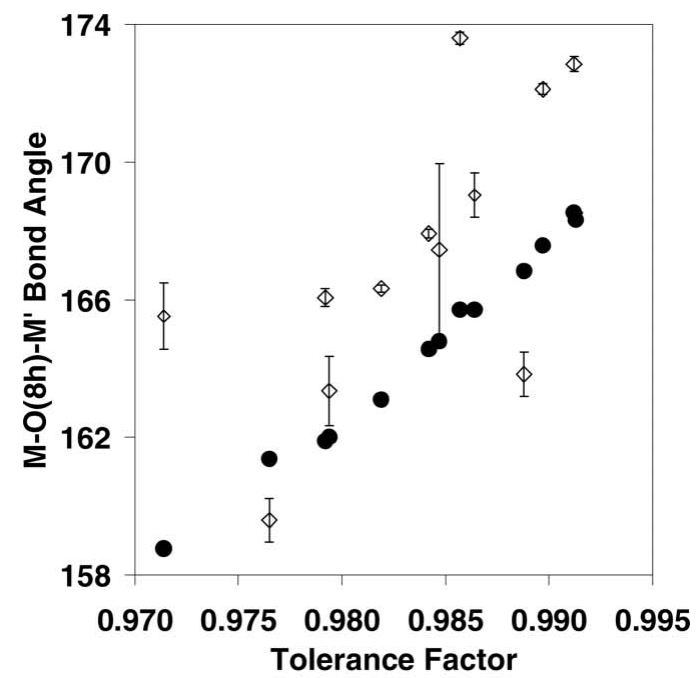

(a)

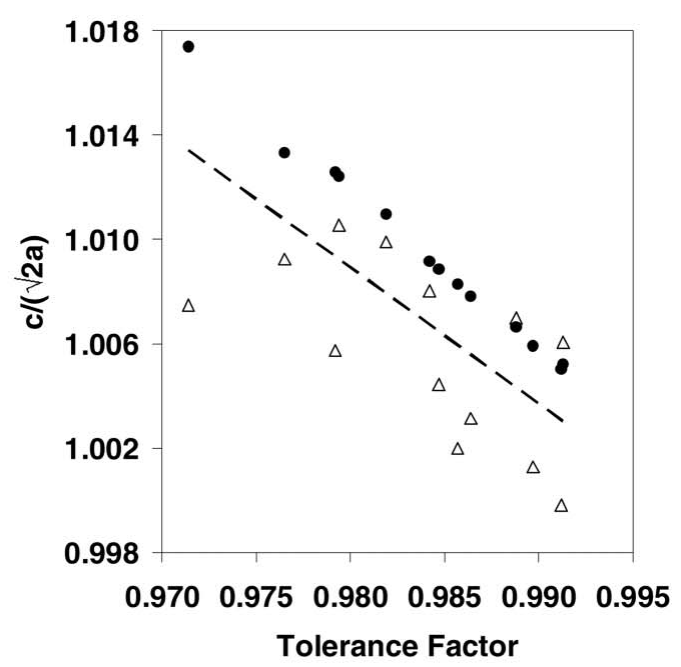

(b)

Figure 2

Structural features of $I 4 / m$ perovskites (a) $M-\mathrm{O}(8 h)-M^{\prime}$ bond angle versus tolerance factor. Filled circles represent $S P U D S$ predicted values and open diamonds experimental values. (b) Lattice parameter ratio $\left[c /\left(2^{1 / 2} a\right)\right]$ versus tolerance factor. Filled circles represent SPuDS predicted structures; open triangles represent experimental values. The uncertainty is smaller than the symbol size. metal ions, particularly $d^{0}$ transition metal ions, are more prevalent (see Table 3). Once again we see a tendency for the calculations to overestimate the magnitude of octahedral tilting. In some cases the fairly large discrepancy between calculated and observed structures can be partially attributed to mixed valency of the octahedral cations. For example, in both $\mathrm{Ba}_{2} \mathrm{TbBiO}_{6}$ and $\mathrm{Ba}_{2} \mathrm{PrBiO}_{6}$ there is a partial charge transfer from the rare-earth ion to the $\mathrm{Bi}$ atom, which gives rise to intermediate oxidation states of $3+/ 4+$ for the rareearth ion and 3+/5+ for bismuth (Harrison et al., 1995). In $\mathrm{Ba}_{2} \mathrm{PrBiO}_{6}$ the situation is further complicated by octahedral site mixing of approximately $25 \%$. In the absence of these effects the calculated atomic positions are in reasonably good agreement with the observed atomic positions.

Inspection of Table 4 also leads to some interesting observations regarding pseudosymmetry. First of all, note that regardless of the tilt angle the calculated value of the monoclinic angle, $\beta$, remains exactly $90^{\circ}$. From this fact we infer that $a^{0} b^{-} b^{-}$tilting creates a structure with monoclinic symmetry but a unit cell with orthorhombic dimensions. The small deviations from $90^{\circ}$ that are observed must originate from distortions of the octahedra. Secondly, notice that, although the $A$-site cation is free to move anywhere on the mirror plane on which it sits, the displacement from $\left(0,0, \frac{1}{4}\right)$ is minimal in both the observed and the calculated structures. This fact is a validation of the argument made in the previous article that $A$-site cation displacements are negligible in tilt systems where only out-of-phase octahedral tilts occur. Finally, note that $S P U D S$ consistently generates a unit cell where $b>a$, and in some cases the two values differ significantly. This aspect of the calculations is not in very good agreement with the experimental observations. Among the experimental values not only is the difference between the lengths of the $a$ and $b$ axes considerably smaller than predicted; in some cases $b<a$ in direct contradiction to the predictions. It is a general trend in both $A M X_{3}$ and $A_{2} M M^{\prime} X_{6}$ perovskites and a number of tilt systems that $S P U D S$ consistently predicts the splitting of the $a$, $b$ and $c$ axes to be larger than observed experimentally. As $S P U D S$ is fairly accurate in predicting the tilt angles, this discrepancy must originate in distortions of the octahedra. Why these distortions occur in such a way so as to minimize the distortion of the cell parameters from cubic values is not understood. We will return to this point in more detail in our treatment of $P 2_{1} / n\left(a^{-} a^{-} b^{+}\right)$perovskites.

\section{4. $R \overline{3}\left(a^{-} a^{-} a^{-}\right)$}

Equal tilts about all three axes of the cubic cell, tilt system $a^{-} a^{-} a^{-}$, is the equivalent of a single tilt, $\Phi$, about the [111] direction of the aristotype structure. When rock-salt cation ordering and $a^{-} a^{-} a^{-}$tilting are combined the result is a structure with $R \overline{3}$ space-group symmetry. The fractional positions are $A(x, x, x)$ with $x \simeq \frac{1}{4}, M(0,0,0), M^{\prime}\left(\frac{1}{2}, \frac{1}{2}, \frac{1}{2}\right)$, and $X(x, y, z)$ with $x \simeq \frac{1}{4}, y \simeq \frac{1}{4}, z \simeq \frac{1}{4}$. As with the $a^{0} b^{-} b^{-}$tilt system there are relatively few reported examples of $a^{-} a^{-} a^{-}$ tilting among ordered perovskites. Examples include 
Table 4

Experimental and $S P U D S$ predicted lattice parameters, $A$-site cation positions, and tilt angles for selected $a^{0} b^{-} b^{-}$ $(I 2 / m)$ compositions.

The $M$-site cation listed first in the formula is located at the origin $(0,0,0)$ and the second is at $\left(\frac{1}{2}, \frac{1}{2}, 0\right)$.

\begin{tabular}{llllllllll}
\hline Formula & Method & $a(\AA)$ & $b(\AA)$ & $c(\AA)$ & $\beta\left(^{\circ}\right)$ & $A x$ & $A z$ & $M-\mathrm{O}-M^{\prime}\left(^{\circ}\right)$ & Ref. \\
\hline $\mathrm{BaLaCoRuO}_{6}$ & XRPD & $5.6266(2)$ & $5.6416(3)$ & $7.9856(4)$ & $90.12(2)$ & $-0.0033(4)$ & $0.2516(3)$ & $165(1)$ & $(a)$ \\
& SPuDS & 5.6994 & 5.7501 & 8.0602 & 90.0 & -0.0021 & 0.2503 & 169.3 & \\
$\mathrm{Ba}_{2} \mathrm{TbBiO}_{6}$ & NPD & $6.1104(2)$ & $6.0813(3)$ & $8.5922(4)$ & $89.97(2)$ & $0.002(2)$ & $0.249(3)$ & $167.3(6)$ & $(b)$ \\
& SPuDS & 6.0584 & 6.2451 & 8.5679 & 90.0 & 0.011 & 0.252 & 160.2 & \\
$\mathrm{Ba}_{2} \mathrm{PrBiO}_{6}$ & NPD & $6.2011(2)$ & $6.1583(2)$ & $8.6968(3)$ & $89.922(5)$ & $0.0036(7)$ & $0.250(2)$ & $164.8(4)$ & $(b)$ \\
& SPuDS & 6.1264 & 6.3950 & 8.6640 & 90.0 & 0.017 & 0.254 & 156.6 & \\
$\mathrm{Ba}_{2} \mathrm{NdBiO}_{6}$ & NPD & $6.1776(2)$ & $6.1366(2)$ & $8.6686(3)$ & $89.801(2)$ & $0.0032(4)$ & $0.2511(4)$ & $165.6(1)$ & $(b)$ \\
& SPuDS & 6.1054 & 6.3483 & 8.6344 & 90.0 & 0.015 & 0.253 & 157.6 & \\
$\mathrm{Sr}_{2} \mathrm{TeNiO}_{6}$ & NPD & $5.6166(1)$ & $5.5807(1)$ & $7.8797(1)$ & $90.048(2)$ & $0.0018(4)$ & $0.2492(3)$ & $168.8(3)$ & $(c)$ \\
& SPuDS & 5.5884 & 5.625 & 7.9032 & 90.0 & 0.0013 & 0.2497 & 166.8 & \\
\hline
\end{tabular}

References: (a) Kim \& Battle (1995), (b) Harrison et al. (1995), (c) Martin et al. (2005).

Table 5

Experimental and SPUDS predicted lattice parameters and free fractional coordinates for selected $a^{-} a^{-} a^{-}$ compounds.

The $M$-site cation listed first in the formula is located at the origin $(0,0,0)$ and the second is at $\left(\frac{1}{2}, \frac{1}{2}, \frac{1}{2}\right)$.

\begin{tabular}{llllllllll}
\hline Formula & Method & $a(\AA)$ & $\alpha\left(^{\circ}\right)$ & $A x$ & $\mathrm{O} x$ & $\mathrm{O} y$ & $\mathrm{O} z$ & $M-\mathrm{O}-M^{\prime}\left({ }^{\circ}\right)$ & Ref. \\
\hline $\mathrm{Ba}_{2} \mathrm{BiYbO}_{6}$ & NPD & $6.0252(2)$ & $60.037(2)$ & $0.2508(15)$ & $-0.2210(4)$ & $-0.2687(4)$ & $0.242(2)$ & $172.2(3)$ & $(a)$ \\
& SPuDS & 6.1068 & 59.05 & 0.250 & -0.184 & -0.305 & 0.244 & 160.7 & \\
$\mathrm{Ba}_{2} \mathrm{BiSbO}_{6}$ & NPD & $6.0424(2)$ & $60.178(5)$ & $0.2566(6)$ & $-0.2319(3)$ & $-0.2984(3)$ & $0.2729(7)$ & $168.9(2)$ & $(b)$ \\
& SPuD & 6.1181 & 58.96 & 0.250 & -0.2068 & -0.3336 & 0.2708 & 159.7 & \\
$\mathrm{Ba}_{2} \mathrm{BiTaO}_{6}$ & NPD & $6.0513(2)$ & $60.285(1)$ & $0.2498(2)$ & $-0.2258(3)$ & $-0.3108(12)$ & $0.2688(5)$ & $166.2(2)$ & $(c)$ \\
& SPuDS & 6.0918 & 59.06 & 0.2500 & -0.2114 & -0.3317 & 0.2721 & 160.7 & \\
$\mathrm{Ba}_{2} \mathrm{BiBiO}_{6}$ & NPD, 419 K & $6.1440(2)$ & $60.309(1)$ & $0.2513(9)$ & $-0.2147(3)$ & $-0.3071(2)$ & $0.2593(2)$ & $165.04(7)$ & $(d)$ \\
& SPuDS & 6.2601 & 58.44 & 0.250 & -0.1849 & -0.3412 & 0.2637 & 155.3 & \\
\hline
\end{tabular}

References: (a) Harrison et al. (1995), (b) Fu (2000), (c) Zhou \& Kennedy (2005), (d) Thornton \& Jacobson (1978).

sequence of phase transitions in these two compounds is $P 2_{1} / n$ $\left(a^{-} a^{-} b^{+}\right) \Rightarrow I 2 / m\left(a^{0} b^{-} b^{-}\right)$ $\Rightarrow R \overline{3}\left(a^{-} a^{-} a^{-}\right)$. The failure to observe the $I 2 / \mathrm{m}$ phase may be attributed to the difficulty in detecting the continuous phase transition in a DSC measurement and the lack of neutron powder data across a more closely spaced temperature interval.

The lattice parameters and free fractional coordinates calculated by $S P U D S$ are compared with the reported values in Table 5 . In each calculation, $S P U D S$ predicts the $A$-site cation to remain exactly on the highsymmetry position $\left(\frac{1}{4}, \frac{1}{4}, \frac{1}{4}\right)$, although not required to do so by symmetry. This observation is consistent with the comments made in the previous section that out-of-phase octahedral tilting by itself does not induce displacements of the $A$-site cation. In the reported crystal structures

$\mathrm{Ba}_{2} \mathrm{Bi}^{3+} \mathrm{Bi}^{5+} \mathrm{O}_{6}$ (Cox \& Sleight, 1979), $\mathrm{Ba}_{2} \mathrm{Bi}^{3+} \mathrm{Sb}^{5+} \mathrm{O}_{6}(\mathrm{Fu}$, 2000), $\mathrm{Ba}_{2} \mathrm{Yb}^{3+} \mathrm{Bi}^{5+} \mathrm{O}_{6}$ (Harrison et al., 1995), $\mathrm{Ba}_{2} \mathrm{BiTaO}_{6}$ (Zhou \& Kennedy, 2005) and $\mathrm{La}_{2} \mathrm{MnMO}_{6}(M=\mathrm{Ni}$ and $\mathrm{Co}$; Bull et al., 2003). There are several similarities between the $R \overline{3}$ $\left(a^{-} a^{-} a^{-}\right)$and $I 2 / m\left(a^{0} b^{-} b^{-}\right)$tilt systems, including the prevalence of main group ions in high oxidation states and phase transitions between the two tilt systems. Both $\mathrm{Ba}_{2} \mathrm{Bi}^{3+} \mathrm{Bi}^{5+} \mathrm{O}_{6}$ and $\mathrm{Ba}_{2} \mathrm{Bi}^{3+} \mathrm{Sb}^{5+} \mathrm{O}_{6}$ transform from $I 2 / m$ $\left(a^{0} b^{-} b^{-}\right)$to $R \overline{3}\left(a^{-} a^{-} a^{-}\right)$upon warming. Among $\mathrm{Ba}_{2} M \mathrm{BiO}_{6}$ compositions at room temperature there is a crossover from $I 2 / m$ symmetry, observed for $M=\mathrm{Pr}, \mathrm{Nd}$ and $\mathrm{Tb}$, to $R \overline{3}$ symmetry, observed for $\mathrm{Ba}_{2} \mathrm{YbBiO}_{6}$, as the ionic radius of the rare-earth ion decreases (Harrison et al., 1995). Both observations are indicative of a transformation from $I 2 / m\left(a^{0} b^{-} b^{-}\right)$ to $R \overline{3}\left(a^{-} a^{-} a^{-}\right)$as the effective tolerance factor increases. Somewhat different behavior is reported for $\mathrm{La}_{2} \mathrm{MnCoO}_{6}$ and $\mathrm{La}_{2} \mathrm{MnNiO}_{6}$. For these two compounds a transition from $P 2_{1} / n$ $\left(a^{-} a^{-} b^{+}\right)$to $R \overline{3}\left(a^{-} a^{-} a^{-}\right)$has been reported based on differential scanning calorimetry (DSC) data and analysis of neutron powder diffraction patterns collected at room temperature and elevated temperature, $623 \mathrm{~K}(M=\mathrm{Ni})$ and $673 \mathrm{~K}(M=\mathrm{Co})$. However, it has been shown that the $P 2_{1} / n$ $\left(a^{-} a^{-} b^{+}\right)$to $I 2 / m\left(a^{0} b^{-} b^{-}\right)$transition can be continuous (Howard et al., 2003), so it is quite possible that the actual the $A$-site cation position is not found exactly at $\left(\frac{1}{4}, \frac{1}{4}, \frac{1}{4}\right)$, but in most cases the displacement away from this position is very small.

\section{5. $\operatorname{Pn} \overline{3}\left(a^{+} a^{+} a^{+}\right)$}

The first example of a perovskite that exhibits $a^{+} a^{+} a^{+}$tilting was reported by Deschanvres et al. (1967). Following this initial work, a sizeable family of compounds was produced through a sustained exploration of high-pressure hightemperature synthesis (Bochu et al., 1974; Chenavas et al., 1975; Ozaki et al., 1977). This family of perovskites has been the focus of considerable interest in recent years owing to the discovery of unusual dielectric properties in $\mathrm{CaCu}_{3} \mathrm{Ti}_{4} \mathrm{O}_{12}$ (Subramanian et al., 2000). This is the only tilt system belonging to group $B$, where the $A$-site cations are not equivalent, that $S P U D S$ has been programmed to model. This was a conscious decision based on the rarity of other tilt systems belonging to group $B$. The occurrence of $a^{+} a^{+} a^{+}$tilting creates two sites for the $A$-site cations with very different chemical environments. For example, in $\mathrm{CaCu}_{3} \mathrm{Ti}_{4} \mathrm{O}_{12}$ the $\mathrm{Ca}^{2+}$ ion is icosohedrally coordinated with $12 \mathrm{Ca}-\mathrm{O}$ bonds of equal length [2.608 (1) $\AA$ ] , whereas the $\mathrm{Cu}^{2+}$ ions have four very 
Table 6

Experimental and SPUDS predicted lattice parameters and free fractional coordinates for selected $a^{+} a^{+} a^{+}(P n \overline{3})$ compounds.

The $M$-site cation listed first in the formula is located at the origin $(0,0,0)$ and the second is at $\left(\frac{1}{2}, \frac{1}{2}, \frac{1}{2}\right)$.

\begin{tabular}{llllllll}
\hline Formula & Method & $a(\AA)$ & $\mathrm{O} x$ & $\mathrm{O} y$ & $\mathrm{O} z$ & $M-\mathrm{O}-M^{\prime}\left({ }^{\circ}\right)$ & $\mathrm{Ref}$ \\
\hline $\mathrm{CaCu}_{3} \mathrm{Ga}_{2} \mathrm{Sb}_{2} \mathrm{O}_{12}$ & NPD & $7.4483(4)$ & $0.2526(4)$ & $0.42799(9)$ & $0.55454(8)$ & $140.3(1)$ & $(a)$ \\
& SPuDS & 7.5064 & 0.2484 & 0.4278 & 0.5560 & 140.5 & - \\
$\mathrm{CaCu}_{3} \mathrm{Ga}_{2} \mathrm{Ta}_{2} \mathrm{O}_{12}$ & NPD & $7.4663(2)$ & $0.2497(8)$ & $0.4282(1)$ & $0.5542(1)$ & $140.4(3)$ & $(a)$ \\
& SPuDS & 7.4794 & 0.2499 & 0.4291 & 0.5552 & 140.5 & - \\
\hline
\end{tabular}

References: (a) Byeon et al. (2003).

short bonds $[1.978(1) \AA]$ and a coordination environment that is close to square planar. The square planar environment is particularly favorable for small transition metal ions with a Jahn-Teller electron configuration, such as $\mathrm{Cu}^{2+}$ or $\mathrm{Mn}^{3+}$. Thus $a^{+} a^{+} a^{+}$tilting goes hand in hand with 1:3 ordering of the $A$-site cations.

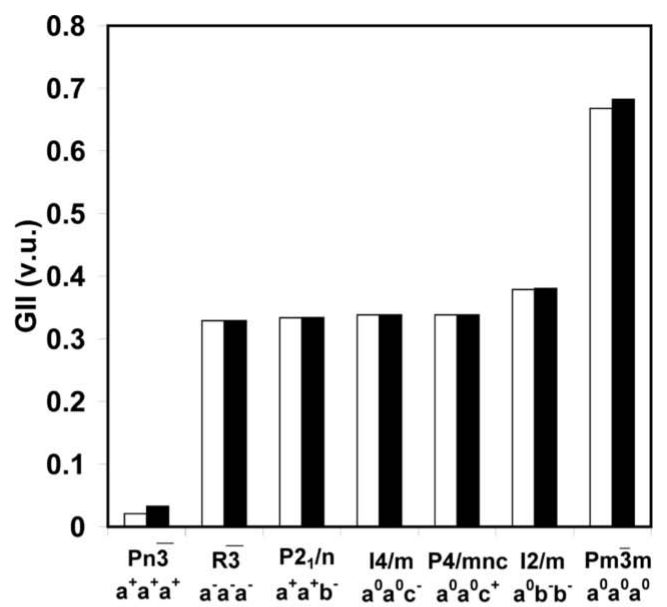

(a)

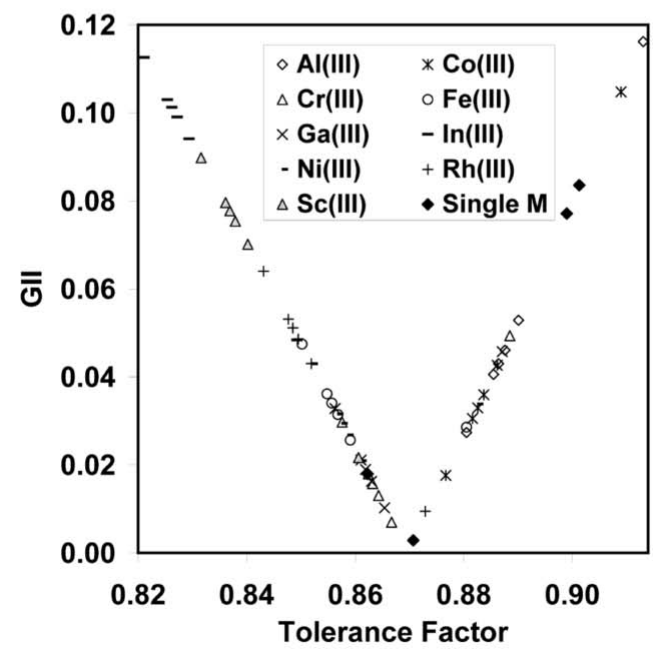

Figure 3

(b)

(a) GII versus tilt system for $\mathrm{CaCu}_{3} \mathrm{Ga}_{2} \mathrm{Ta}_{2} \mathrm{O}_{12}$ (white) and $\mathrm{CaCu}_{3-}$ $\mathrm{Ga}_{2} \mathrm{Sb}_{2} \mathrm{O}_{12}$ (black). (b) GII versus tolerance factor of the SPuDS optimized structures for $P n \overline{3}$ perovskites. The tolerance factors of compounds containing these ions on the $M^{\prime}$ site follow the order $\mathrm{Sb}^{5+}<$ $\mathrm{Ta}^{5+}<\mathrm{Ir}^{5+}<\mathrm{Nb}^{5+}<\mathrm{Ru}^{5+}<\mathrm{V}^{5+}$.
Perovskites with simultaneous 1:1 rock-salt ordering of the octahedral site cations and $a^{+} a^{+} a^{+}$tilting, stabilizing 1:3 ordering of the $A$-site cations, crystallize with $P n \overline{3}$ spacegroup symmetry. The fractional positions of the atoms are $A 1\left(\frac{1}{4}, \frac{1}{4}, \frac{1}{4}\right)$, $A 2\left(\frac{1}{4}, \frac{3}{4}, \frac{3}{4}\right), M(0,0,0), M^{\prime}\left(\frac{1}{2}, \frac{1}{2}, \frac{1}{2}\right)$ and $X(x, y, z)$ with $x \simeq \frac{1}{4}, y \simeq \frac{1}{2}$ and $z \simeq \frac{1}{2}$. The $a^{+} a^{+} a^{+}$tilt system is different from those discussed thus far in one important aspect. This tilt system has little flexibility because any change in the tilt angle impacts the $A-X$ distances of the squareplanar site much more dramatically than the $A-X$ distances of the icosohedral site. This effect tends to inhibit changes in the tilt angle that are brought about either by substitution of ions of varying size or by changes in temperature and/or pressure. This situation differentiates $a^{+} a^{+} a^{+}$perovskites from all of the tilt systems that belong to group $A$ (see Table 1). It also means that the radii of all elements involved must be mutually compatible if a stable structure is to result. These facts make $S P U D S$ a particularly useful tool to guide synthetic attempts. In that spirit, $S P U D S$ was used in the structure prediction and analysis of dual $A, M$-site ordered $\mathrm{CaCu}_{3}$ $\mathrm{Ga}_{2} \mathrm{Ta}_{2} \mathrm{O}_{12}, \mathrm{CaCu}_{3} \mathrm{Ga}_{2} \mathrm{Sb}_{2} \mathrm{O}_{12}$ and $\mathrm{CaCu}_{3} \mathrm{Cr}_{2} \mathrm{Sb}_{2} \mathrm{O}_{12}$, as well as $\mathrm{CaCu}_{3} \mathrm{Ga}_{2} \mathrm{Nb}_{2} \mathrm{O}_{12}$ where the $M$-site cation distribution was disordered (Byeon et al., 2003, 2004, 2005). Prior to the synthesis of $\mathrm{CaCu}_{3} \mathrm{Ga}_{2} M_{2} \mathrm{O}_{12}(M=\mathrm{Sb}$ and Ta) there were no reports in the literature of perovskites that simultaneously showed $a^{+} a^{+} a^{+}$tilting and rock-salt order of the octahedral cations. The calculated structural variables for these two compounds are compared with the reported values in Table 6 . The agreement is quite good. The GII values obtained via $S P U D S$ optimization for these two compounds in six different tilt systems is shown in Fig. 3(a). From this figure it is clear that the $a^{+} a^{+} a^{+}$tilt system will be strongly preferred over competing quintinary perovskite phases. Of course, it is more difficult to predict the stability with respect to multiphase mixtures.

The predicted stability of compositions of potential $P n \overline{3}$ perovskites was briefly examined in a previous study (Byeon $e t$ al., 2003). A more detailed analysis of compounds predicted to favor crystallization in the space group $P n \overline{3}$ was undertaken by identifying potential $\mathrm{CaCu}_{3} M_{2} M_{2}^{\prime} \mathrm{O}_{12}$ combinations. An examination of likely candidates was undertaken using combinations of trivalent $\left(\mathrm{Al}^{3+}, \mathrm{Co}^{3+}, \mathrm{Cr}^{3+}, \mathrm{Ga}^{3+}, \mathrm{Ni}^{3+}, \mathrm{Fe}^{3+}\right.$, $\mathrm{Rh}^{3+}, \mathrm{Sc}^{3+}$ and $\left.\mathrm{In}^{3+}\right)$ and pentavalent $\left(\mathrm{V}^{5+}, \mathrm{Ru}^{5+}, \mathrm{Nb}^{5+}, \mathrm{Ir}^{5+}\right.$, $\mathrm{Ta}^{5+}$ and $\mathrm{Sb}^{5+}$ ) octahedral site cations. This analysis led to 54 potential $P n \overline{3}$ double perovskites, whose GII values are plotted versus tolerance factor in Fig. 3(b). The ideal tolerance factor for $P n \overline{3}$ perovskites with $\mathrm{CaCu}_{3} M_{2} M^{\prime}{ }_{2} \mathrm{O}_{12}$ stoichiometry is roughly 0.87 . The structure becomes less stable owing to the overbonding of the $\mathrm{Cu}^{2+}$ ion and underbonding of the $\mathrm{Ca}^{2+}$ ion for $\tau<0.87$, while the opposite is true for $\tau>0.87$. Interestingly, among all of the compounds modeled, $\mathrm{CaCu}_{3} \mathrm{Ti}_{4} \mathrm{O}_{12}$ has the lowest GII. This fact helps to explain why it is one of the 
Table 7

Literature and $S P U D S$ predicted lattice parameters and free fractional positions with tolerance factors for $\mathrm{La}_{2} \mathrm{NiRuO}_{6}, \mathrm{Ca}_{2} \mathrm{SbFeO}_{6}$ and $\mathrm{La}_{2} \mathrm{LiSbO}_{6}$ perovskites (space group $\left.P 2_{1} / n\right)$ having tilt system $a^{-} a^{-} b^{+}$.

The $M$-site cation listed first in the formula is located at $\left(0, \frac{1}{2}, 0\right)$ and the second is at $\left(\frac{1}{2}, 0,0\right)$.

\begin{tabular}{llllllll}
\hline Formula & Method & $a(\AA)$ & $b(\AA)$ & $c(\AA)$ & $\beta\left(^{\circ}\right)$ & $\tau$ & Ref. \\
\hline $\mathrm{La}_{2} \mathrm{NiRuO}_{6}$ & NPD & $5.5688(4)$ & $5.5984(4)$ & $7.8764(6)$ & $90.18(1)$ & & $(a)$ \\
& SPuDS & 5.5099 & 5.6507 & 7.8875 & 90.01 & 0.939 & \\
$\mathrm{Sr}_{2} \mathrm{ErRuO}_{6}$ & NPD & $5.7626(2)$ & $5.7681(2)$ & $8.1489(2)$ & $90.19(1)$ & & $(b)$ \\
& SPuDS & 5.7189 & 5.8784 & 8.1952 & 89.9756 & 0.934 & \\
$\mathrm{Ca}_{2} \mathrm{SbFeO}_{6}$ & XRPD & $5.4371(1)$ & $5.5259(1)$ & $7.7340(2)$ & $89.97(1)$ & & $(c)$ \\
& SPuDS & 5.4259 & 5.6048 & 7.7929 & 90.00 & 0.924 & \\
$\mathrm{La}_{2} \mathrm{LiSbO}_{6}$ & NPD & $5.6226(1)$ & $5.7199(1)$ & $7.9689(2)$ & $89.796(9)$ & & $(d)$ \\
& SPuDS & 5.5548 & 5.7550 & 7.9888 & 90.02 & 0.918 & \\
\hline
\end{tabular}

\begin{tabular}{|c|c|c|c|c|c|c|c|}
\hline Formula & Method & $A x$ & $A y$ & $A z$ & $\mathrm{O}(4 e) x$ & $\mathrm{O}(4 e) y$ & $\mathrm{O}(4 e) z$ \\
\hline \multirow[t]{2}{*}{$\mathrm{La}_{2} \mathrm{NiRuO}_{6}$} & NPD & 0.508 (1) & 0.5393 (5) & 0.251 & 0.219 (2) & 0.196 (3) & -0.045 (1) \\
\hline & SPuDS & 0.513 & 0.540 & 0.250 & 0.2 & 0.207 & 040 \\
\hline $\mathrm{Sr}_{2} \mathrm{ErRuO}_{6}$ & $\begin{array}{l}\text { NPD } \\
\text { SPuDS }\end{array}$ & $\begin{array}{l}0.5065(8) \\
0.5145\end{array}$ & $\begin{array}{l}0.5256(4) \\
0.5437\end{array}$ & $\begin{array}{l}0.2518 \\
0.2517\end{array}$ & $\begin{array}{l}0.2021(8) \\
0.1902\end{array}$ & $\begin{array}{l}0.2303(8) \\
0.2272\end{array}$ & $\begin{array}{l}-0.0332(5) \\
-0.0420\end{array}$ \\
\hline $\mathrm{Ca}_{2} \mathrm{SbFeO}_{6}$ & $\begin{array}{l}\text { XRPD } \\
\text { SPuDS }\end{array}$ & $\begin{array}{l}0.5085 \text { (1) } \\
0.518\end{array}$ & $\begin{array}{l}0.5435(3) \\
0.552\end{array}$ & $\begin{array}{l}0.2489 \\
0.250\end{array}$ & $\begin{array}{l}0.211 \text { (3) } \\
0.204\end{array}$ & $\begin{array}{l}0.202(3) \\
0.208\end{array}$ & $\begin{array}{l}-0.036(5) \\
-0.046\end{array}$ \\
\hline $\mathrm{La}_{2} \mathrm{LiSbO}_{6}$ & $\begin{array}{l}\text { NPD } \\
\text { SPuDS }\end{array}$ & $\begin{array}{l}0.5101(3) \\
0.520\end{array}$ & $\begin{array}{l}0.5442(2) \\
0.557\end{array}$ & $\begin{array}{l}0.2535 \\
0.249\end{array}$ & $\begin{array}{l}0.2133(5) \\
0.210\end{array}$ & $\begin{array}{l}0.1949(5) \\
0.198\end{array}$ & $\begin{array}{l}-0.0420(4) \\
-0.048\end{array}$ \\
\hline Formula & Method & $\mathrm{O}(4 e)^{\prime} x$ & $\mathrm{O}(4 e)^{\prime} y$ & $\mathrm{O}(4 e)^{\prime} z$ & $\mathrm{O}(4 e)^{\prime \prime} x$ & $\mathrm{O}(4 e)^{\prime \prime} y$ & $\mathrm{O}(4 e)^{\prime \prime} z$ \\
\hline \multirow[t]{2}{*}{$\mathrm{La}_{2} \mathrm{NiRuO}_{6}$} & NPD & $0.294(2)$ & $0.715(2)$ & $-0.038(1)$ & $0.422(1)$ & $-0.0139(7)$ & $0.250(1)$ \\
\hline & SPuDS & 0.295 & 0.717 & -0.0 & 0.4 & -0.012 & 0.245 \\
\hline \multirow[t]{2}{*}{$\mathrm{Sr}_{2} \mathrm{ErRuO}_{6}$} & NPD & $0.2672(7)$ & $0.7036(7)$ & $-0.0339(6)$ & $0.4330(7)$ & $-0.0124(6)$ & 0.2635 (4) \\
\hline & SPuDS & 0.2741 & 0.6934 & -0.0419 & 0.4161 & -0.0143 & 0.2674 \\
\hline \multirow[t]{2}{*}{$\mathrm{Ca}_{2} \mathrm{SbFeO}_{6}$} & XRPD & $0.305(3)$ & 0.707 (3) & $-0.045(4)$ & $0.415(3)$ & $-0.025(2)$ & 0.248 (3) \\
\hline & SPuDS & 0.295 & 0.707 & -0.046 & 0.409 & -0.016 & 0.250 \\
\hline \multirow[t]{2}{*}{$\mathrm{La}_{2} \mathrm{LiSbO}_{6}$} & NPD & $0.3005(5)$ & $0.7179(4)$ & $-0.0456(4)$ & 0.4132 & -0.0219 (3) & $0.2394(4)$ \\
\hline & SPuDS & 0.306 & 0.713 & -0.048 & 0.404 & -0.017 & 0.242 \\
\hline
\end{tabular}

References: (a) Seinen et al. (1987), (b) Battle et al. (1991), (c) Lee et al. (1997), (d) López et al. (1992).

few $a^{+} a^{+} a^{+}$perovskites that can be prepared without resorting to high-pressure synthesis. Based on the GII values for $A^{\prime} A_{3} M_{4} \mathrm{O}_{12}$ compositions that have been prepared by highpressure high-temperature synthesis techniques, it is reasonable to expect that compounds with a GII less than approximately 0.09 can form single-phase $a^{+} a^{+} a^{+}$perovskites (Lufaso \& Woodward, 2001). The calculation values plotted in Fig. $3(b)$ reveal many compositions with GII $<0.09$, indicating numerous potentially stable compositions. It is also interesting to ask what compositions might be formed if the $A$-site cations are not $\mathrm{Ca}^{2+}$ and $\mathrm{Cu}^{2+}$. The perovskites $\mathrm{Sr}_{1-x} \mathrm{Cu}_{3}{ }_{-y} \mathrm{Ti}_{y} \mathrm{Ti}_{4} \mathrm{O}_{12}$ (Li et al., 2004), $\mathrm{SrMn}_{3} \mathrm{Mn}_{4} \mathrm{O}_{12}$ (Bochu et al., 1974) and $\mathrm{SrCu}_{3} \mathrm{Ru}_{4} \mathrm{O}_{12}$ (Ebbinghaus et al., 2002) represent the only examples where $\mathrm{Sr}^{2+}$ has replaced $\mathrm{Ca}^{2+}$ on the icosahedral site. However, to the best of our knowledge, there have been no reports of $\mathrm{SrCu}_{3} M_{2} M_{2}^{\prime} \mathrm{O}_{12}$ perovskites. SPuDS may be used to generate promising candidates for high-pressure hightemperature synthesis, which is described in a forthcoming paper.

\section{6. $P 2_{1} / n\left(a^{-} a^{-} b^{+}\right)$}

Double perovskites with octahedral cation ordering and $a^{-} a^{-} b^{+}$octahedral tilting crystallize in the space group $P 2_{1} / n$, which is the ordered perovskite equivalent of the $\mathrm{GdFeO}_{3}$ structure (space group Pnma, tilt system $a^{-} b^{+} a^{-}$). As is the case for $A M X_{3}$ perovskites, this is the most prevalent tilt system for ordered double perovskites. The octahedral cations are located on fixed positions $M\left(0, \frac{1}{2}, 0\right)$ and $M^{\prime}\left(\frac{1}{2}, 0,0\right)$, whereas the $A$-site cation and each of the three crystallographically distinct anions are located on general positions. Four example compounds $-\mathrm{La}_{2} \mathrm{NiRuO}_{6}$ (Seinen et al., 1987), $\mathrm{Sr}_{2} \mathrm{ErRuO}_{6}$ (Battle et al., 1991), $\mathrm{Ca}_{2} \mathrm{SbFeO}_{6}$ (Lee et al., 1997) and $\mathrm{La}_{2} \mathrm{LiSbO}_{6}$ (López et al., 1992) - were chosen to illustrate the accuracy of the SPUDS structure calculations in detail. The calculated structures are compared with those reported in the literature in Table 7. A broader evaluation of the accuracy of $S P u D S$ for predicting structures of $P 2_{1} / n$ perovskites is displayed in Figs. 4 and 5. A complete list of the compounds that were used to generate Figs. 4 and 5 can be found in the supporting material. ${ }^{4}$ These figures clearly show that as the tolerance factor decreases the tilt angle systematically increases, as do the $x$ and $y$ coordinates of the $A$-site cation. The calculated variation of the tilt angle with tolerance factor is in very good agreement with the observed tilt angles. ${ }^{5}$ A similar degree of accuracy was previously reported for $A M X_{3}$ perovskites (Lufaso \& Woodward, 2001).

The octahedral tilt angle used in SPuDS is a single tilt angle that is a combination of the rotation about a [110] axis and a [001] axis normal to the original, which was described previously for the Pnma-type perovskites (O'Keeffe \& Hyde, 1977). A coupled tilt angle is utilized because the two tilt angles are not truly independent tilt angles but are related in the rigid octahedral assumption. The TUBERS software calculated the tilt angle for both the coupled tilt angle and the individual tilt axes. The single coupled octahedral tilt angle is plotted versus tolerance factor in Fig. 5(a), while the relationship between the single coupled tilt angle and the individual tilt angles about the [110] and [001] axes are shown in Fig. 5(b).

There is an essentially linear relationship between the calculated value of the $A$-site cation displacement in the $x y$ plane and the tolerance factor. The experimental values follow the same general trend, albeit with a considerable amount of scatter in the data, but unlike the calculated trend the $A$-site cation displacement tends to saturate as the tolerance factor decreases. Even for moderate degrees of tilting SPuDS tends to slightly overestimate the displacement of the $A$-site cation. The $z$ coordinate of the $A$-site cation deviates very little from

\footnotetext{
${ }^{4}$ Supplementary data for this paper are available from the IUCr electronic archives (Reference: WS5032). Services for accessing these data are described at the back of the journal.

${ }^{5}$ The observed value of an average tilt angle was calculated from the fractional coordinates of the oxygen ions, $M-X$ distances and lattice parameters using the program TUBERS.
} 
$\frac{1}{4}$, the value it would possess in the absence of tilting. Furthermore, it shows no dependence on the tolerance factor.

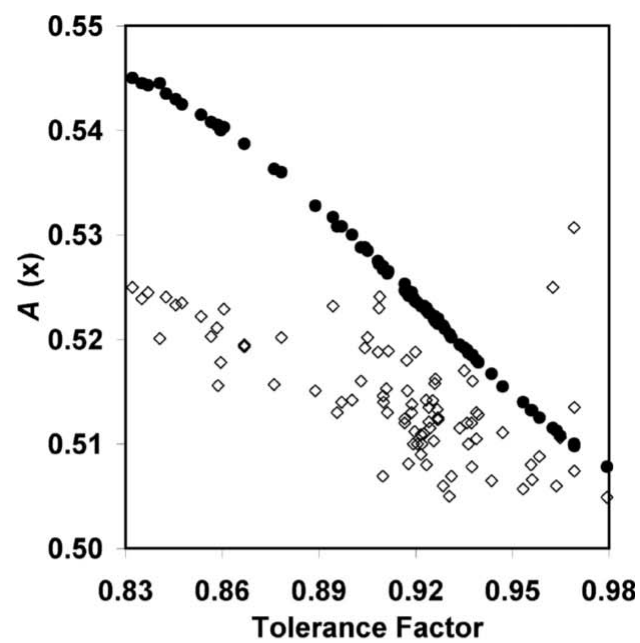

(a)

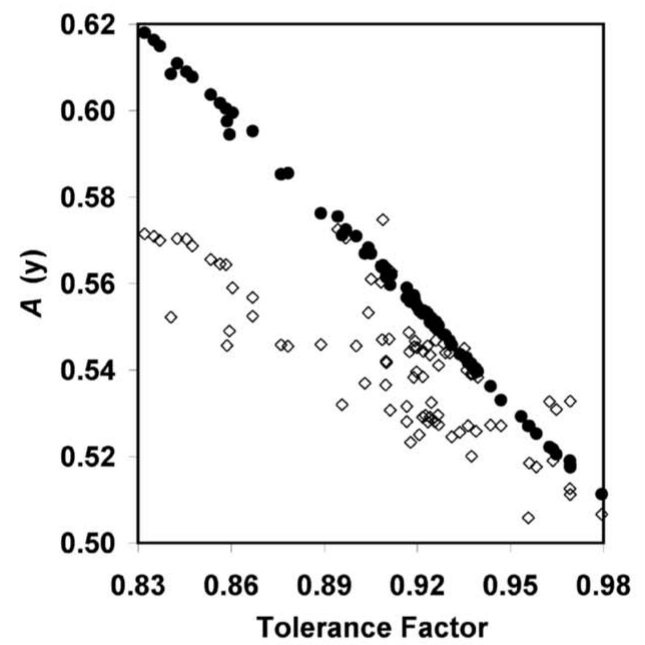

(b)

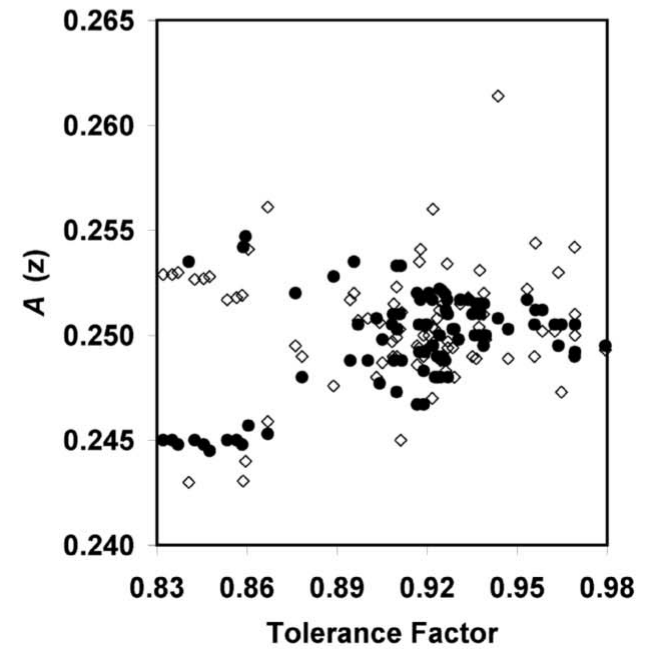

(c)

Figure 4

Comparison of literature and $S P u D S$ predicted $A$-site fractional positions of $a^{-} a^{-} b^{+} P 2_{1} / n$ perovskites. Filled circles are $S P u D S$ predicted values and open diamonds are experimental values.
This observation is not unexpected, because in $A M X_{3}$ perovskites that undergo $a^{-} a^{-} b^{+}$tilting the $A$-site cation lies on a mirror plane and the $A$-site position is $\left(x, y, \frac{1}{4}\right)$ (using the Pbnm setting). While the different identities and sizes of the $M$ and $M^{\prime}$ cations destroy the strict symmetry of the mirror plane, the oxygen ions are still related by a pseudo-mirror plane unless the $M$ and $M^{\prime}$ cations differ significantly in size.

As discussed in the preceding article many perovskites exhibit a high degree of pseudosymmetry. Furthermore, it was suggested that the pseudosymmetry exhibited by $\mathrm{Sr}_{2} M^{3+} M^{5+} \mathrm{O}_{6}$ perovskites was more pronounced than the pseudosymmetry of $\mathrm{Ca}_{2} M^{3+} M^{5+} \mathrm{O}_{6}$ perovskites (Barnes et al., 2006). To investigate this further a comparison of the reduced

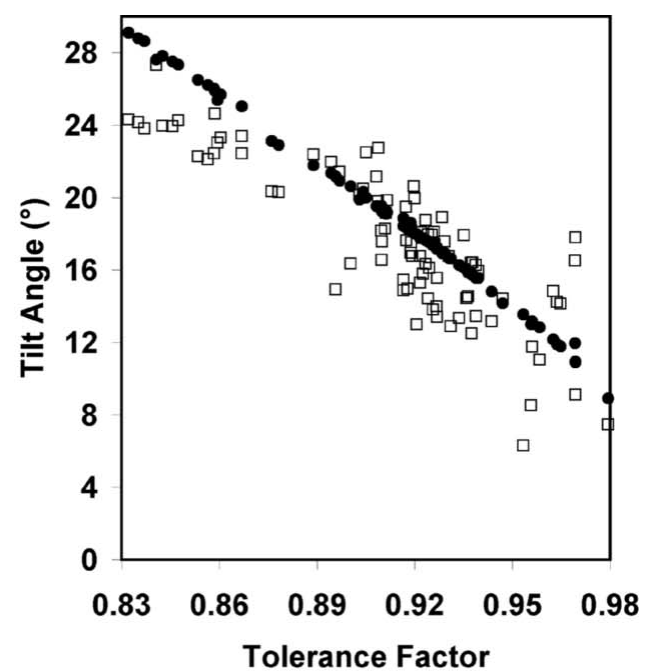

(a)

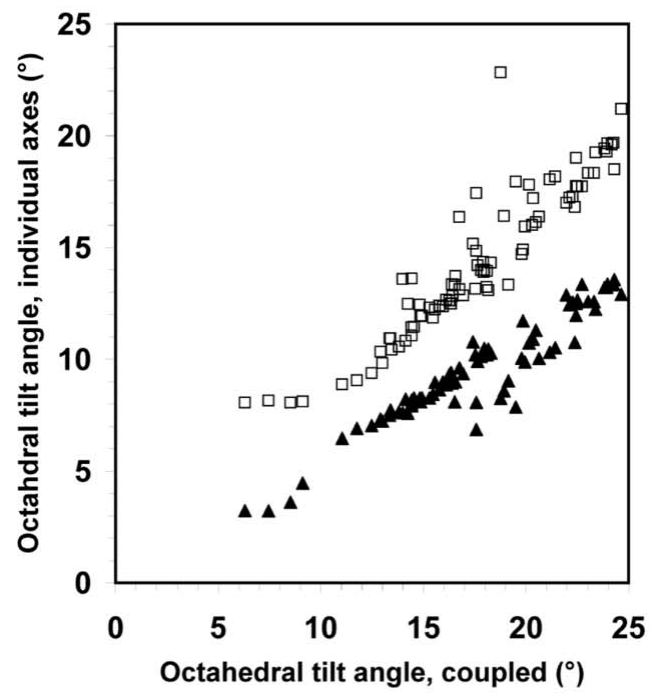

(b)

Figure 5

(a) Comparison of literature and SPUDS predicted coupled tilt angle versus tolerance factor, where filled circles are $S P u D S$ predicted values and open squares are experimental values. $(b)$ The average octahedral tilt angles of $a^{-} a^{-} b^{+} P 2 / n$ perovskites calculated from the experimental cell parameters and atomic coordinates using the equations of Groen et al. (1986). The $x$ axis is the average octahedral tilt angle calculated using a coupled tilt angle and the $y$ axis contains the octahedral tilt angle about the [001] (filled triangles) and [110] (open squares) axes. 


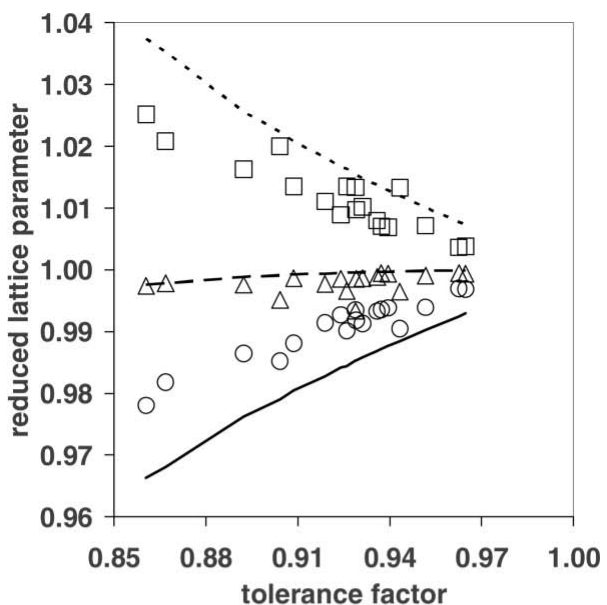

(a)

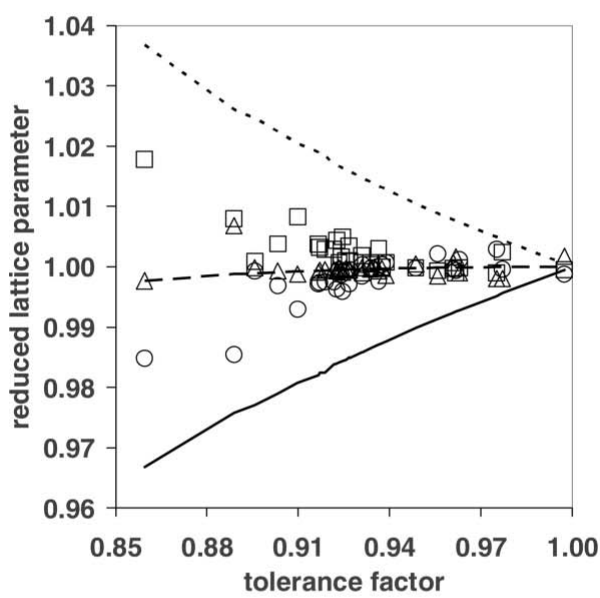

(b)

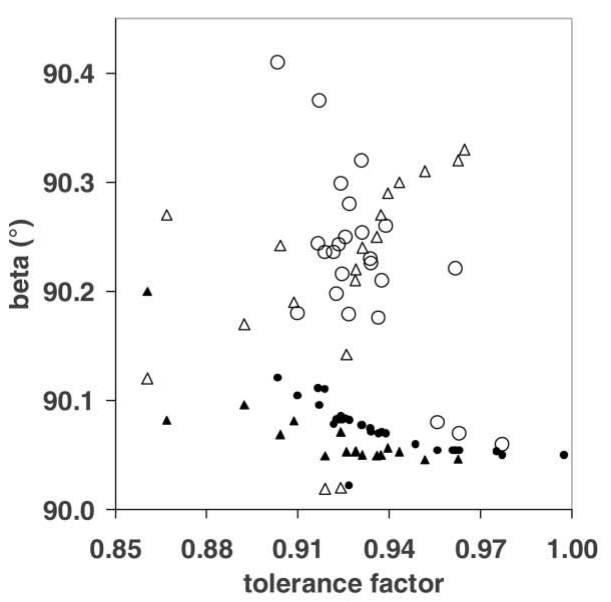

(c)

Figure 6

Reduced lattice parameter versus tolerance factor for monoclinic $(a)$ $\mathrm{Ca}_{2} M^{3+} M^{5+} \mathrm{O}_{6}$ and $(b) \mathrm{Sr}_{2} M^{3+} M^{5+} \mathrm{O}_{6}$ double perovskites. Circles represent $a$, squares represent $b$ and triangles represent the $c$ pseudocubic lattice parameter. Thick lines represent $a$, dotted lines represent $b$, and dashed lines represent $c$-reduced lattice parameters predicted by $S P u D S$. (c) Monoclinic $\beta$ angle, where open and filled symbols (circles: $\mathrm{Sr}_{2} M^{3+} M^{5+} \mathrm{O}_{6}$; triangles: $\mathrm{Ca}_{2} M^{3+} M^{5+} \mathrm{O}_{6}$ ) represent literature and $S P u D S$ predicted double perovskites, respectively. pseudo-cubic lattice parameters for $\mathrm{Sr}_{2} M^{3+} M^{5+} \mathrm{O}_{6}$ and $\mathrm{Ca}_{2} M^{3+} M^{5+} \mathrm{O}_{6}$ monoclinic perovskites is shown in Fig. 6. Reduced pseudo-cubic lattice parameters are useful for comparing cell constants of perovskites that cover a large range of unit-cell volumes. They are calculated by converting each of the three lattice parameters into a value that is $\sim 2 a_{\mathrm{p}}$, where $a_{\mathrm{p}}$ is the cubic cell edge of a $\operatorname{Pm} \overline{3} m$ perovskite. The deviation from an orthorhombic cell is neglected, which is a valid approximation because $\beta \simeq 90^{\circ}$ in almost all cases (see also Fig. $6 c$ ). After converting the lattice parameters to their pseudo-cubic counterparts, the reduced lattice parameters were computed using cell constants found in the literature for $\mathrm{Ca}$ and $\mathrm{Sr}$ compounds, and theoretical values were determined by $S P u D S$ using the equation

$$
a_{\mathrm{r}}=a_{\mathrm{pc}} / V^{1 / 3},
$$

where $a_{\mathrm{r}}$ is the reduced lattice parameter, $a_{\mathrm{pc}}$ is the pseudocubic cell constant $\left(=2^{1 / 2} a\right)$ and $V$ is $2^{1 / 2} a \times 2^{1 / 2} b \times c$. If $a_{\mathrm{r}}, b_{\mathrm{r}}$ and $c_{\mathrm{r}}$ are all equal to 1 , the lattice is metrically cubic. As the lattice metric distorts from cubic, $a_{\mathrm{r}}, b_{\mathrm{r}}$ and $c_{\mathrm{r}}$ will deviate from 1. Figs. $6(a)$ and $6(b)$ show that the magnitude of the orthorhombic distortion is calculated to increase smoothly for both strontium and calcium compounds as octahedral tilting increases. The value of the monoclinic angle $\beta$ is plotted in Fig. $6(c)$. The calculated values of $\beta$ deviate very little from $90^{\circ}$ showing that the basic orthorhombic unit-cell dimensions are essentially preserved by tilting of rigid octahedra. The reason for the inherent orthorhombic pseudosymmetry can be traced to the fact that $a^{-} a^{-} b^{+}$tilting by itself only lowers the symmetry to orthorhombic. The further reduction to monoclinic symmetry occurs in response to cation ordering. Much like the displacement of the $A$-site cation in the $z$ direction, there is little driving force for deviation from the orthorhombic value unless the radii of the $M$ and $M^{\prime}$ cations differ significantly.

The experimental values plotted in Fig. 6 reveal a more complicated situation. For $\mathrm{Ca}_{2} M M^{\prime} \mathrm{O}_{6}$ perovskites the orthorhombic distortion increases with decreasing tolerance factor, following the basic trend predicted by SPuDS. The calculated distortion of the unit cell is somewhat larger than the actual distortion, following the trend observed in every previous tilt system. More than anything else this discrepancy between calculation and experiment probably indicates that while tilting of rigid octahedra is the primary mechanism for obtaining the lowest-energy configuration, small distortions of the octahedra play a secondary role in this process. The situation is very different for $\mathrm{Sr}_{2} M M^{\prime} \mathrm{O}_{6}$ perovskites. Here the reduced cell parameters are all closely bunched around 1.00 and show little dependence on tolerance factor. Part of this result can be attributed to the fact that the tolerance factors of $\mathrm{Sr}_{2} M M^{\prime} \mathrm{O}_{6}$ perovskites do not go much below $\tau=0.92$. Nonetheless, over the tolerance factor range where both $\mathrm{Sr}_{2} M M^{\prime} \mathrm{O}_{6}$ and $\mathrm{Ca}_{2} M M^{\prime} \mathrm{O}_{6}$ compounds coexist the orthorhombic distortion of the strontium compounds is on average much smaller than that of the calcium compounds. This effect is not limited to ordered perovskites; it also exists for ternary 
perovskites. Consider, for example, the reduced lattice parameters of the Pbnm perovskite $\mathrm{CaTiO}_{3}(\tau=0.946), a_{\mathrm{r}}=0.9937$, $b_{\mathrm{r}}=1.0069$ and $c_{\mathrm{r}}=0.9994$ (Ranjan et al., 1999) in comparison to $\mathrm{SrSnO}_{3}(\tau=0.957), a_{\mathrm{r}}=1.0007, b_{\mathrm{r}}=0.9997$ and $c_{\mathrm{r}}=0.9996$ (Green et al., 2000). While both compounds have considerable pseudo-cubic character, the deviations of $a_{\mathrm{r}}$ and $b_{\mathrm{r}}$ in $\mathrm{CaTiO}_{3}$, which are the two parameters most sensitive to tilting, deviate from unity by an amount that is an order of magnitude larger than in $\mathrm{SrSnO}_{3}$. The origin of this effect is not understood. It is a question that warrants further theoretical consideration.

\section{Conclusions}

The software program SPuDS has been developed for predicting the crystal structures of perovskite compounds, including those with multiple octahedral cations and octahedral tilting distortions. Detailed analysis of the results for several octahedral tilt systems and a large number of compounds indicates that the method is an accurate approach to modeling the crystal structures of ordered perovskites. Calculated global instability index (GII) values are useful in determining the relative stability of the composition in a particular tilt system. A large difference in GII for untilted and tilted compositions implies that the structure is relatively unstable and likely to undergo an octahedral tilting distortion. Structures reported in the literature with a large GII that were refined from low-resolution X-ray diffraction data may require reexamination with higher-resolution X-ray diffraction data or neutron diffraction data to ensure that the crystal structure is correct. It is anticipated that a careful inspection of structures reported in disordered $P m \overline{3} m$ or ordered $F m \overline{3} m$ would uncover some compounds where octahedral tilting distortions have occurred and the true symmetry is lower.

In general, crystal structures predicted using SPuDS provide a useful and reliable starting model for Rietveld refinements. Thus, it can be used to simplify the structure refinement process, particularly for perovskites crystallizing in space groups with many degrees of freedom $\left(\right.$ e.g. $\left.P 2_{1} / n\right)$. A comparison of predicted and observed structures reveals a tendency for the unit-cell parameters to distort somewhat less than expected for rotations of rigid octahedra. This tendency for enhanced pseudosymmetry is particularly pronounced in $\mathrm{Sr}_{2} M M^{\prime} \mathrm{O}_{6}$ perovskites.

\section{References}

Aleksandrov, K. S. (1976). Kristallografiya, 21, 249-255.

Aleksandrov, K. S. \& Misyul, S. V. (1981). Sov. Phys. Crystallogr. 26, 612-618.

Alonso, J. A., Cascales, C., Casado, P. G. \& Rasines, I. (1997). J. Solid State Chem. 128, 247-250.

Amador, U., Hetherington, C. J. D., Moran, E. \& Alario-Franco, M. A. (1992). J. Solid State Chem. 96, 132-140.

Anderson, M. T., Greenwood, K. B., Taylor, G. A. \& Poeppelmeier, K. R. (1993). Prog. Solid State Chem. 22, 197-233.

Arulraj, A., Ramesha, K., Gopalakrishnan, J. \& Rao, C. N. R. (2000). J. Solid State Chem. 155, 233-237.
Azad, A. K., Ivanov, S. A., Eriksson, S. G., Eriksen, J., Rundlof, H., Mathieu, R. \& Svedlindh, P. (2001). Mater. Res. Bull. 36, 2215-2228.

Baldinozzi, G., Grebille, D., Sciau, P., Kiat, J. M., Moret, J. \& Berar, J. F. (1998). J. Phys. Condens. Matter, 10, 6461-6472.

Baldinozzi, G., Sciau, P., Pinot, M. \& Grebille, D. (1995). Acta Cryst. B51, 668-673.

Barnes, P. W. (2003). PhD thesis, Ohio State University, USA.

Barnes, P. W., Lufaso, M. W. \& Woodward, P. M. (2006). Acta Cryst. B62, 384-396.

Battle, P. D. \& Jones, C. W. (1989). J. Solid State Chem. 78, 108-116.

Battle, P. D., Jones, C. W. \& Studer, F. (1991). J. Solid State Chem. 90, 302-312.

Bochu, B., Chenavas, J., Joubert, J. C. \& Marezio, M. (1974). J. Solid State Chem. 11, 88-93.

Bock, O. \& Müller, U. (2002). Acta Cryst. B58, 594-606.

Bokhimi (1992). Powder Diffr. 7, 228-230.

Brese, N. E. \& O'Keeffe, M. (1991). Acta Cryst. B47, 192-197.

Brown, I. D. (1978). Chem. Soc. Rev. 7, 359-376.

Bull, C. L., Gleeson, D. \& Knight, K. S. (2003). J. Phys. Condens. Matter, 15, 4927-4936.

Byeon, S. H., Lee, S. S., Parise, J. B., Woodward, P. M. \& Hur, N. H. (2004). Chem. Mater. 16, 3697-3701.

Byeon, S. H., Lee, S. S., Parise, J. B., Woodward, P. M. \& Hur, N. H. (2005). Chem. Mater. 17, 3552-3557.

Byeon, S. H., Lufaso, M. W., Parise, J. B., Woodward, P. M. \& Hansen, T. (2003). Chem. Mater. 15, 3798-3804.

Chenavas, J., Jourbet, J. C., Marezio, M. \& Bochu, B. (1975). J. Solid State Chem. 14, 25-32.

Chmaissem, O., Kruk, R., Dabrowski, B., Brown, D. E., Xiong, X., Kolesnik, S., Jorgensen, J. D. \& Kimball, C. W. (2000). Phys. Rev. B, 62, 14197-14206.

Choy, J. H., Hong, S. T. \& Choi, K. S. (1996). J. Chem. Soc. Faraday Trans. 92, 1051-1059.

Cox, D. E. \& Sleight, A. W. (1979). Acta Cryst. B35, 1-10.

Deschanvres, A., Raveau, B. \& Tollemer, F. (1967). Bull. Soc. Chim. Fr. 11, 4077-4078.

Dianoux, A. J. \& Poix, P. (1968). C. R. Acad. Sci. C Chim. 266, $283-$ 285.

Doi, Y. \& Hinatsu, Y. (2001). J. Phys. Condens. Matter, 13, 4191-4202.

Doi, Y., Hinatsu, Y., Nakamura, A., Ishii, Y. \& Morii, Y. (2003). J. Mater. Chem. 13, 1758-1763.

Ebbinghaus, S. G., Weidenkaff, A. \& Cava, R. J. (2002). J. Solid State Chem. 167, 126-136.

Fu, W. T. (2000). Solid State Commun. 116, 461-464.

Fu, W. T. \& Ijdo, D. J. W. (1997). J. Solid State Chem. 128, 323-325.

Fu, W. T. \& Ijdo, D. J. W. (2005a). J. Solid State Chem. 178, 1312-1316.

Fu, W. T. \& Ijdo, D. J. W. (2005b). J. Solid State Chem. 178, 2363-2367.

Gateshki, M. \& Igartua, J. M. (2004). J. Phys. Condens. Matter, 16, 6639-6649.

Gateshki, M., Igartua, J. M. \& Hernandez-Bocanegra, E. (2003). J. Phys. Condens. Matter, 15, 6199-6217.

Glazer, A. M. (1972). Acta Cryst. B28, 3384-3392.

Goldschmidt, V. M. (1926). Naturwissenschaften, 14, 477.

Green, M. A., Prassides, K., Day, P. \& Neumann, D. A. (2000). Int. J. Inorg. Mater. 2, 35-41.

Grenet, J. C., Poix, P. \& Michel, A. (1972). Ann. Chim. (Paris), 1972, 231-234.

Groen, W. A., Vanberkel, F. P. F. \& Ijdo, D. J. W. (1986). Acta Cryst. C42, 1472-1475.

Halasyamani, P. S. (2004). Chem. Mater. 16, 3586-3592.

Halasyamani, P. S. \& Poeppelmeier, K. R. (1998). Chem. Mater. 10, 2753-2769.

Harrison, W. T. A., Reis, K. P., Jacobson, A. J., Schneemeyer, L. F. \& Waszczak, J. V. (1995). Chem. Mater. 7, 2161-2167.

Hewat, A. W. (1973). J. Phys. C Solid State Phys. 6, 2559-2572.

Hinatsu, Y., Izumiyama, Y., Doi, Y., Alemi, A., Wakeshima, M., Nakamura, A. \& Morii, Y. (2004). J. Solid State Chem. 177, 3844. 
Howard, C. J., Kennedy, B. J. \& Woodward, P. M. (2003). Acta Cryst. B59, 463-471.

Howard, C. J., Luca, V. \& Knight, K. S. (2002). J. Phys. Condens. Matter, 14, 377-387.

Howard, C. J. \& Stokes, H. T. (2004). Acta Cryst. B60, 674-684.

Howard, C. J. \& Stokes, H. T. (2005). Acta Cryst. A61, 93-111.

Hutton, J., Nelmes, R. J. \& Scheel, H. J. (1981). Acta Cryst. A37, 916920.

Iwanaga, D., Inaguma, Y. \& Itoh, M. (1999). J. Solid State Chem. 147, 291-295.

Izumiyama, Y., Doi, Y., Wakeshima, M., Hinatsu, Y., Nakamura, A. \& Ishii, I. (2002). J. Solid State Chem. 169, 125-130.

Jung, D.-Y., Gravereau, P. \& Demazeau, G. (1993). Eur. J. Solid State Inorg. Chem. 30, 1025-1037.

Karunadasa, H., Huang, Q., Ueland, B. G., Schiffer, P. \& Cava, R. J. (2003). Proc. Natl Acad. Sci. USA, 100, 8097-8102.

Kim, S. H. \& Battle, P. D. (1995). J. Solid State Chem. 114, 174-183.

Kwei, G. H., Lawson, A. C., Billinge, S. J. L. \& Cheong, S. W. (1993). J. Phys. Chem. 97, 2368-2377.

Lee, S. O., Cho, T. Y. \& Byeon, S. H. (1997). Bull. Korean Chem. Soc. 18, 91-97.

Li, J., Subramanian, M. A., Rosenfeld, H. D., Jones, C. Y., Toby, B. H. \& Sleight, A. W. (2004). Chem. Mater. 16, 5223-5225.

Li, L. Q. \& Kennedy, B. J. (2004). J. Solid State Chem. 177, 3290-3300.

López, M. L., Veiga, M. L., Rodríguez-Carvajal, J., Fernández, F., Jerez, A. \& Pico, C. (1992). Mater. Res. Bull. 27, 647-654.

Lufaso, M. W. (2002). PhD thesis, The Ohio State University, USA.

Lufaso, M. W. \& Woodward, P. M. (2001). Acta Cryst. B57, 725-738.

Lufaso, M. W. \& Woodward, P. M. (2004). Acta Cryst. B60, 10-20.

Martin, L. O. S., Chapman, J. P., Cuello, G., Gonzalez-Calbet, J., Arriortua, M. I. \& Rojo, T. (2005). Z. Anorg. Allg. Chem. 631, 2127-2130.

Martinez-Lope, M. J., Alonso, J. A. \& Casais, M. T. (2003). Eur. J. Inorg. Chem. pp. 2839-2844.

Martinez-Lope, M. J., Alonso, J. A., Casais, M. T. \& Fernandez-Diaz, M. T. (2002). Eur. J. Inorg. Chem. pp. 2463-2469.

Nguyen, N., Sriti, F., Martin, C., Bouree, F., Greneche, J., Ducouret, A., Studer, F. \& Raveau, B. (2002). J. Phys. Condens. Matter, 14, $12629-12640$

O'Keeffe, M. \& Hyde, B. G. (1977). Acta Cryst. B33, 3802-3813.

Ortega-San Martin, L., Chapman, J. P., Lezama, L., Sanchez-Marcos, J., Rodriguez-Fernandez, J., Arriortua, M. I. \& Rojo, T. (2005). J. Mater. Chem. 15, 183-193.

Ouchetto, K., Archaimbault, F., Pineau, A. \& Choisnet, J. (1991). J. Mater. Sci. Lett. 10, 1277-1279.

Ozaki, Y., Ghedira, M., Chenavas, J., Joubert, J. C. \& Marezio, M. (1977). Acta Cryst. B33, 3615-3617.
Patwe, S. J., Achary, S. N. \& Tyagi, A. K. (2005). J. Alloys Compd, 390, 100-105.

Rammeh, N., Bramnik, K. G., Ehrenberg, H., Stahl, B., Fuess, H. \& Cheikh-Rouhou, A. (2004). J. Alloys Compd. 363, 24-31.

Ranjan, R., Pandey, D., Siruguri, V., Krishna, P. S. R. \& Paranjpe, S. K. (1999). J. Phys. Condens. Matter, 11, 2233-2246.

Rao, G. H., Barner, K. \& Brown, I. D. (1998). J. Phys. Condens. Matter, 10, L757-L763.

Reinen, D. \& Weitzel, H. (1976). Z. Anorg. Allg. Chem. 424, 3138.

Sakowski-Cowley, A. C., Lukaszewicz, K. \& Megaw, H. D. (1969). Acta Cryst. B25, 851-865.

Salinas-Sanchez, A., Garcia-Munoz, J. L., Rodriguez-Carvajal, J., Saez-Puche, R. \& Martinez, J. L. (1992). J. Solid State Chem. 100, 201-211.

Sasaki, S., Prewitt, C. T., Bass, J. D. \& Schulze, W. A. (1987). Acta Cryst. C43, 1668-1674.

Seinen, P. A., Vanberkel, F. P. F., Groen, W. A. \& Ijdo, D. J. W. (1987). Mater. Res. Bull. 22, 535-542.

Stitzer, K. E., Smith, M. D. \& zur Loye, H. C. (2002). Solid State Sci. 4, 311-316.

Subramanian, M. A., Li, D., Duan, N., Reisner, B. A. \& Sleight, A. W. (2000). J. Solid State Chem. 151, 323-325.

Taira, N. \& Hinatsu, Y. (2000). J. Solid State Chem. 150, 31-35.

Tao, S., Canales-Vazquez, J. \& Irvine, J. T. S. (2004). Chem. Mater. 16, 2309-2316.

Tezuka, K., Henmi, K., Hinatsu, Y. \& Masaki, N. M. (2000). J. Solid State Chem. 154, 591-597.

Thornton, G. \& Jacobson, A. J. (1978). Acta Cryst. B34, 351354.

Viola, M. C., Martinez-Lope, M. J., Alonso, J. A., Velasco, P., Martinez, J. L., Pedregosa, J. C., Carbonio, R. E. \& Fernandez-Diaz, M. T. (2002). Chem. Mater. 14, 812-818.

Wiebe, C. R., Greedan, J. E., Kyriakou, P. P., Luke, G. M., Gardner, J. S., Fukaya, A., Gat-Malureanu, I. M., Russo, P. L., Savici, A. T. \& Uemura, Y. J. (2003). Phys. Rev. B, 68, 134410.

Woodward, P. M. (1997a). Acta Cryst. B53, 32-43.

Woodward, P. M. (1997b). PhD thesis, Oregon State University, USA.

Woodward, P. M. (1997c). Acta Cryst. B53, 44-66.

Woodward, P. M. \& Baba-Kishi, K. Z. (2002). J. Appl. Cryst. 35, $233-$ 242.

Woodward, P. M., Sleight, A. W. \& Vogt, T. (1997). J. Solid State Chem. 131, 9-17.

Zhao, Y. S., Weidner, D. J., Parise, J. B. \& Cox, D. E. (1993). Phys. Earth Planet Inter. 76, 1-16.

Zhou, Q. D. \& Kennedy, B. J. (2005). Solid State Sci. 7, 287-291.

Zhou, J. S. \& Goodenough, J. B. (2005). Phys. Rev. Lett. 94, 065501. 